\title{
ASENTISTAS Y FABRICANTES: EL ABASTECIMIENTO DE ARMAS Y MUNICIONES AL ESTADO EN LOS SIGLOS XVII Y XVIII*
}

\section{Contractors and Manufacturers: Supplying Arms and Ammu- nition to the Spanish State in XVII and XVIII Centuries}

\author{
Agustín GONZÁLEZ ENCISO \\ Universidad de Navarra \\ Correo-e: agenciso@unav.es
}

RESUMEN: El artículo estudia cómo resolvía el Estado español el abastecimiento de armas en los siglos XVII y XVIII según la fórmula empresarial utilizada: qué tipo de empresario y qué tipo de organización empresarial. Ello lleva, en primer lugar, a una somera, pero necesaria descripción del sector, en concreto, la fabricación de cañones, de municiones y de fusiles. Esta parte incluye consideraciones sobre la organización empresarial y sobre los aspectos técnicos. El cuerpo del trabajo estudia la figura de los asentistas en cada sector: quiénes eran, qué otros negocios tenían, cuáles eran las características de los asientos, cuál era su relación con la Administración, si desarrollaban vínculos familiares, etc. Hasta 1760 dominó el abastecimiento por asiento, pero tras esa fecha el Estado cambió, en unos cuantos casos, hacia otras fórmulas, para pasar a ser un Estado fabricante. La última parte del artículo estudia esta época, sus circunstancias y las consecuencias que trajo en la producción, en el abastecimiento y en los empresarios.

Palabras clave: asentistas, fabricantes, industria de armamento, abastecimiento de municiones, siglos XVII y XVIII, España.

Este trabajo forma parte del Proyecto de Investigación financiado por el Ministerio de Economía y Competitividad, HAR2011-23570. 
ABSTRACT: This paper deals with the problem of provisioning arms and ammunition by the Spanish state during the XVII and XVIII centuries according to the types of entrepreneur (the asentista or contractor) involved and the characteristics of the organisation developed. First, there is a formal description of the arms industrial sector (cannons, ammunition, muskets), touching such aspects as industrial organisation and the technology implied. The body of the paper goes on the figure of the asentista in each subsector: who were them, if they had other business, what were the characteristics of the contracts and the real relation with the Administration, if they developed family links in their business, and so on. Up to 1760 , contracting by the state was dominant, but afterwards the policy was changed in several sectors so the state became a manufacturer state, owner of his factories. The last part of the paper focuses on this period, looking at the circumstances and consequences of that change of policy on provisioning and on the entrepreneurs.

Key words: Contractors, Manufacturers, Arms Industry, Ammunition Supply, xvir and xviII Centuries, Spain.

\section{INTRODUCCIÓN}

¿Cómo resolvía el Estado español el problema del abastecimiento de armas en los siglos XVII y XVIII, qué fórmula empresarial utilizaba? Una respuesta inmediata a estas preguntas puede llevarnos a equívoco, porque la realidad es que la solución pasó por fórmulas muy variadas. Una cosa es cierta, sin embargo: en el centro de todas las soluciones está el asentista. El asentista es un tipo social aún poco conocido, a pesar de los trabajos que sobre esta figura han ido apareciendo ${ }^{1}$; no obstante, es un personaje clave para explicar las posibilidades económicas y políticas de un gobierno que se enfrenta a la guerra, porque el asentista actúa como interfaz entre la sociedad en general, con sus recursos humanos, materiales y dinerarios, y el aparato estatal que tiene que valerse de esos recursos. La eventual ausencia de asentistas, cuando eso sucede, es igualmente explicativa, aunque en un sentido diferente. En todos los casos se trata de funciones complementarias de cara a la construcción del Estado y a sus posibilidades militares.

El asentista sirve a un proyecto político, por lo tanto, detrás de su actividad están tanto las necesidades políticas, como los problemas y el modo de resolverlos;

1. El trabajo de Rafael Torres, que encabeza esta sección monográfica, es un buen ejemplo de la cantidad de conocimiento que hoy tenemos sobre el mundo de los asientos en el siglo XviII. A él me remito. 
además, por supuesto, están las personas que tenían que tomar decisiones al respecto. Asentistas y políticos se encuentran estrechamente relacionados en la medida en que la suerte de los primeros dependía de la manera de enfocar la cuestión de los segundos, a la vez que los políticos tuvieron que apoyarse en la capacidad empresarial y negociadora de los asentistas para poder abastecer de los géneros necesarios al Ejército y a la Marina.

Ahora bien, como las necesidades y las soluciones fueron diferentes según los sectores, si bien los problemas generales podían ser similares, obtuvieron respuestas empresariales diferentes según el ámbito de que se tratara. Detrás latía el eterno problema del comprar o fabricar, un problema que no existía en todas las parcelas del abastecimiento. Así, los tipos de negocio a que dio lugar la provisión de armas no fueron los mismos que existían en el sector de los víveres (alimentos, en general), o del vestuario (tejidos) ${ }^{2}$. Lo que sabemos para unos casos no siempre se puede aplicar a otros. ¿Cómo y en qué condiciones de organización empresarial, desempeñaron los asentistas su tarea y en particular, cómo lo hicieron en el sector del armamento?

Además de los distingos según el sector o el producto, hay que tener en cuenta los cambios en el tiempo. Por una parte, se ven más continuidades que diferencias entre los siglos XVII y XVIII; por otra parte, en cambio, considerar el siglo XVIII como un todo es impropio casi siempre, al menos en nuestro sector, porque hay modificaciones entre unos momentos y otros del siglo, particularmente en la fabricación de armamento pesado, pues los gobernantes de turno llegaron a tomar decisiones que abocaron a cambios drásticos en la estructura empresarial. En concreto, es necesario señalar que después de 1760, la figura del asentista perderá peso en este sector a favor de la Administración, que optó en la mayoría de los casos por una gestión directa, fabricar en vez de comprar.

\section{El SECTOR DEL ARMAMENTO}

A tenor de lo expuesto, este trabajo intenta identificar quiénes eran los asentistas de armamento en la España del siglo XVIII, caracterizar sus facetas principales en tanto comerciantes, negociantes, o fabricantes en su caso, y ubicarles en las circunstancias políticas que les tocara vivir. Pero para entenderlo bien es necesario describir antes el propio sector fabril del armamento desde la perspectiva

2. Ver los trabajos de Torres Sánchez o Solbes Ferri que tratan estas cuestiones, en este mismo monográfico. En el caso de los víveres, por ejemplo, el asentista nunca es el productor, no es un terrateniente que venda sus productos, sino que siempre toma la figura de un comerciante que compra en el mercado y vende luego al Estado. Cosa similar ocurre con el vestuario, donde el asentista tampoco es normalmente el fabricante de los géneros. No ocurre así en el sector del armamento pesado (cañones y su munición), aunque es parecido en el armamento ligero (fusiles y pistolas). 
del mercado; es decir, qué empresas había capaces de realizar ese abastecimiento. Dejamos al margen, en términos generales, cuestiones técnicas y otras posibles que no son del caso aquí, a las que solo aludiremos cuando sea estrictamente necesario.

Pensar en el sector es fundamental, ya que es el mejor modo de ubicarse en las características básicas que tienen la producción y el abastecimiento de un determinado bien o servicio, en las circunstancias económicas y empresariales que lo rodean y por lo tanto, en los aspectos específicos de sus asentistas. Incluso dentro del mismo sector del armamento son diferentes los procesos de fabricación, según productos, y por lo tanto cambia el papel del asentista implicado. Por ejemplo, aunque suele haber una identificación entre fabricante y asentista, no siempre era así. Tampoco los fabricantes lo fueron de la misma manera: podía tratarse de fabricantes individuales o colectivos. El resultado es la existencia de diferentes tipos de empresarios, o bien de diferentes maneras de entender la empresa de abastecimiento de armas al Estado.

La variedad empresarial del sector del armamento, impuesta por el producto fabricado -que lleva a diferentes tipos de fábricas-, tiene que ver también con las diferentes tradiciones de fabricación que existían. Por ejemplo, en la fabricación de cañones de bronce había unos modos tradicionales de hacer que databan de finales del siglo xv y que se mantuvieron en buena medida; en cambio, las fundiciones de hierro no comienzan hasta entrado el siglo XVII y no tienen antecedentes de peso en España.

Empecemos el estudio del sector por el producto más aparatoso, los cañones. Estaban, por una parte, los cañones de bronce. Su fabricación se remonta al siglo XV, al menos ${ }^{3}$. Desde finales del siglo Xv y comienzos del siglo xvi habían existido varias fundiciones en diversos lugares de la Península ${ }^{4}$, también después en las colonias. Probablemente la única fundición permanente durante casi todo el siglo Xvi fue la de Málaga, que aún funcionaba en $1560^{5}$; no obstante, la que se consagraría sería la de Sevilla. Comenzó en 1565 como empresa privada que funcionó, como las anteriores, por el sistema de asientos. Su particularidad reside no solo en la continuidad de su existencia en el mismo cometido, sino en que en 1634 fue comprada por el Estado. A comienzos del siglo xviII subsistía y estaba en buena situación $^{6}$; se mantuvo durante todo el siglo y perviviría después hasta nuestros días.

3. De la Vega Viguera, E.: Sevilla y la Real Fundición de Cañones. Guadalquivir, Sevilla, 1992.

4. CARrasco, A.: «Apuntes para la historia de la fundición de artillería de bronce en España» en Memorial de Artillería, XV, 1887, p. 31; De la Vega Viguera, E.: Sevilla y la Real Fundición.

5. Calvo Poyato, J.: «La industria militar española durante la Guerra de Sucesión», en Revista de Historia Militar, 66 (1989), p. 53.

6. Sobre esta empresa ver Aguilar Escobar, A.: Cañones de bronce para el Ejército. Historia de la Real Fundición de Sevilla en el siglo XVIII. Ministerio de Defensa, Madrid, 2010. 
En las primeras décadas del siglo XVIII aparecieron otras tres empresas en la Península ${ }^{7}$. Al menos en 1716 funcionaba una en Valencia ${ }^{8}$. La de Pamplona trabajó entre 1717 y $1719^{9}$, a cargo del fundidor Matías Solano, que costeó la producción de su bolsillo ${ }^{10}$. Si estas tuvieron una existencia puntual, la de Barcelona, de mayor tradición ${ }^{11}$, se mantuvo activa durante buena parte del siglo ${ }^{12}$. El bronce había sido hasta el siglo XVII casi el único material para fabricar cañones en España (no en otros lugares), tanto para cañones de tierra (de campo y de plazas fuertes), como para artillar los buques ${ }^{13}$. En el siglo XviII siguió usándose para las piezas del ejército y también de las galeras mediterráneas, mientras subsistió esta escuadra, o para alguna pieza pequeña en los navíos.

En España había una larga tradición de trabajo en la metalurgia del bronce -se puede pensar en otros objetos, como las campanas o las estatuas, por ejemplo-, que en líneas generales fue la base de la buena calidad de sus cañones. De todos modos también se notaba la escasez de materia prima, como cuando se compró cobre en Amsterdam, "para fundición de artillería», en $1728^{14}$, o cuando se potenciaba la búsqueda de minas de ese metal en España ${ }^{15}$. Al final del siglo XviII se presentaron más problemas de abastecimiento de materia prima (del cobre indiano, en particular $)^{16}$, pues no se trataba solamente de la fabricación de

7. Parece ser que hubo también una empresa fundidora en Manila, al menos en 1715, aunque no conocemos su alcance. Archivo General de Simancas [en adelante AGS], Secretaría de Guerra [en adelante SG], 703.

8. AGS, SG, 703.

9. Fabricó 88 piezas «y otros» productos, entre cañones y morteros. AGS, SG, 704.

10. Se le debían entonces 1000 doblones por ello. Pamplona, 8 de marzo de 1722, Matías Solano a Castelar. AGS, SG, 705.

11. La de Barcelona parece haber tenido también antecedentes en el siglo XVI, si bien no conocemos su evolución posterior. SUÁREZ MENÉNDEZ, R.: «La industria militar española anterior a 1808», en Militaria. Revista de Cultura Militar, 7 (1995), p. 219. Durante el siglo XvII, dice R. Martí, la ciudad de Barcelona dedicó presupuestos municipales extraordinarios para la fundición de cañones, a causa de las guerras con Francia, pero no precisa más. MARTí, R.: Cataluña armería de los Borbones. Las armas y los armeros de Ripoll, Barcelona, Manresa, Igualada...de 1714 a 1794. Salvatella, Barcelona, 2004, p. 65.

12. Datos sobre algunas producciones y sus fundidores en MARTí, R.: Cataluña Armería de los Borbones, pp. 66-68.

13. SuÁREZ MENÉNDEZ, «La industria militar», pp. 218-219.

14. «Expediente sobre hacer venir de Holanda...», AGS, Secretaría de Marina [en adelante SM], 660. En realidad el cobre era de Noruega, en definitiva, cobre «del norte», como era lo usual.

15. "Que se excuse la extracción de caudales de mis dominios a los extraños, para la compra del preciso metal de cobre que se necesita», se decía en una orden dada en Sevilla, en 16 de septiembre de 1731, por la que se concedían las franquicias y condiciones necesarias para explotar unas minas de cobre en Galicia. AGS, SG Suplemento, 10.

16. Aguilar Escobar, A.: Cañones de bronce, p. 180. Acerca del cobre y su importancia por el aumento de la demanda en España a causa de las numerosas guerras, BARRETT, E.: «Copper in New Spain's Eighteenth Century Economy. Crisis and Resolution", Jahrbuch für Geschichte von Staat, Wirtschaft und Gesellschaft Lateinamerikas, 18 (1981), pp. 73-96. 
cañones, sino de las necesidades creadas al extenderse la técnica de forrar los cascos de los navíos ${ }^{17}$.

Por su parte, la fabricación de cañones de hierro tiene en España una fecha puntual y tardía respecto a otros países ${ }^{18}: 1622$. Entonces comenzó a establecerse la fábrica de Liérganes y La Cavada, que a la larga sería no solo la pionera en España, sino la única que fabricó cañones de hierro colado en España y que pervivió hasta bien entrado el siglo xIx. Como no existía tradición, se introdujo la práctica de Lieja, y se concedió licencia a un asentista fabricante de aquel lugar, conocedor de las técnicas de fundición, que establecería su propia fábrica.

Los cañones exigían su munición, sector en el que la oferta se diversificó algo más. Por supuesto, Liérganes y La Cavada fabricaban sus propias municiones; no obstante, en 1689 se estableció una nueva empresa siderúrgica en Eugui (Navarra), fruto de la transformación de una antigua ferrería real que había trabajado cascos y armaduras desde el siglo xvi. No se trataba de fabricar solamente balas de cañón, sino otro tipo de proyectiles de cañón, mortero y de mano, como granadas, bombas y otros, llamados genéricamente en la época, municiones. Más tarde aparecerían en Navarra otras dos empresas siderúrgicas que contrataron con el rey para la fabricación de todos esos productos, la de Asura, en 1723 y la de Iturbieta, en 1726. Ambas duraron poco, pues habían dejado de abastecer a la Corona al menos en 1739 y 1737 , respectivamente ${ }^{19}$.

La fábrica de Eugui, en cambio, tuvo una mayor duración, pues se mantuvo hasta 1794. Para entonces habían surgido otras tres fábricas de municiones: la de San Sebastián de la Muga, en Gerona, la de Jimena de la Frontera, en Cádiz, y la de Orbaiceta, en Navarra, cuyos establecimientos comenzaron en 1768, 1778 y 1784 , respectivamente ${ }^{20}$. Las tres tuvieron vida efímera y no llegaron al final del siglo. En 1794 aparecieron Sargadelos, en Lugo, y Trubia ${ }^{21}$, en Asturias. En todos los casos, como en el de los cañones de hierro, estas empresas fabricaron con altos hornos.

Las posibilidades de este ramo del sector dependían de factores variados y relativamente escasos. A la rigidez de los recursos naturales, mineral de hierro,

17. Una visión general de esta cuestión en RODRíguez GONZÁLEZ, A. R.: Trafalgar y el conflicto naval anglo-español del siglo XVIII. Madrid, Actas, 2005, pp. 214 y ss.

18. Para la cronología en otros casos y particularmente la ventaja de Inglaterra en las fundiciones de hierro, Cipolla, C.: Guns, Sails and Empires. Minerva Press, s. 1., Nueva York, 1965, pp. 33-36.

19. GonZÁlez ENCISO, A.: "Empresarios navarros en la industria de municiones para la artillería», en TORRes SÁNCHEZ, R. (ed.): Volver a la «hora navarra». La contribución navarra a la construcción de la Monarquía española en el siglo XVIII. EUNSA, Pamplona, 2010, pp. 198-208.

20. Alcalá-Zamora, J.: Altos hornos y poder naval en la España de la Edad Moderna. Real Academia de la Historia, Madrid, 1999, pp. 360 y ss.

21. Adaro Ruiz-Falcó, L.: Los comienzos de las fábricas de municiones gruesas de Trubia y de armas de Oviedo: 1792-1799. Imprenta La Cruz, Oviedo, 1986. 
abundantes bosques y aguas, que obligaban a localizaciones de difícil acceso, había que añadir el capital necesario para establecer los altos hornos. Por otra parte, dado que tanto el mercado privado, como las exportaciones, les estaban vedados a los posibles empresarios, la viabilidad del sector exigía un compromiso claro del Estado, único cliente. Todo ello condicionaría la evolución empresarial de estas actividades.

Problemas distintos plantea el sector de las armas ligeras de uso personal. Nos centraremos solamente en las de fuego. Su manufactura se concentraba en los valles occidentales guipuzcoanos (Éibar, Vergara, Placencia), en Vizcaya ${ }^{22}$ y también en algunas zonas de Cataluña, como en Ripoll, Manresa, Igualada, o en la misma Barcelona ${ }^{23}$. Su organización era gremial. La ventaja de este sector es que tenía la posibilidad de vender también al público -armas de caza, por ejemplo, o a la nobleza-, con lo que no estaba ligado exclusivamente a las necesidades militares, aunque en ocasiones se impuso esa condición. Por otra parte, su establecimiento no dependía tanto de las circunstancias naturales. Durante el reinado de Felipe V, se estableció una nueva fábrica en Silillos, Madrid. Se inauguró hacia 1720, pero se cerró pocos años después por exceso de costes y volvería a tener una vida efímera entre 1769 y 1773, con mayor dependencia de la administración de la Corte ${ }^{24}$.

Como puede verse, el sector de la fabricación de armas en general es pequeño y limitado, una realidad que no deja de sorprender cuando se trata de abastecer a una monarquía, como la española, que no dejó de mantener guerras en toda la Época Moderna. ¿Dónde está la razón del pequeño tamaño?

\section{UN MERCADO ESTRECHO GENERA UNA TECNOLOGÍA ESTANCADA}

Si hacemos excepción de la demanda privada de armas ligeras, lo que tiene en común todo este sector, en cuanto destinado al servicio militar, es la estrechez del mercado y el peso de la coyuntura. La demanda dependía exclusivamente de las necesidades del Estado, y era, además, una demanda errática, condicionada a las urgencias militares. Esto es así porque el Estado no destinó unas cantidades fijas para su abastecimiento de armas, sino que se guió por las necesidades planteadas en cada momento de acción bélica. Cuando se desataba el conflicto y mientras durase, la demanda de armas estaba en activo; pero llegada la paz esa demanda desaparecía. Son habituales las quejas de políticos y militares del siglo

22. Larrañaga, R.: Síntesis Histórica de la Armería Vasca. Caja de Ahorros Provincial de Guipúzcoa, San Sebastián, 1981; SuÁREZ MENÉNDEZ, «La industria militar», p. 219.

23. Ver Martí, R.: Cataluña armería de los Borbones, et passim.

24. Breves menciones sobre esta fábrica en SUÁREZ MENÉNDEZ, «La industria militar», p. 222; Ocete Rubio, R.: Catálogo de armas. Junta de Andalucía, Sevilla, 2008, p. 20. Hay escasa documentación en AGS, SG, 506. 
XVIII sobre la situación desasistida de los instrumentos de guerra: navíos sin artillar, fortalezas con pocos cañones, falta de balas o de pólvora; todo, por supuesto, con guarniciones pequeñas que obviamente usaban un número reducido de armas personales, tantas veces anticuadas.

Esa situación de carencia se intentaba resolver con una febril actividad productiva cuando la guerra se veía inminente. Pero en esos casos ocurría que no siempre había posibilidades de conseguir un abastecimiento inmediato, porque se trataba de productos cuya fabricación no se podía improvisar ${ }^{25}$. En esos casos, curiosamente lo que ocurría es que se rompía el más elemental principio de política mercantilista y había que recurrir al mercado exterior para completar las partidas que la fabricación nacional no era capaz de abastecer en ese momento concreto.

El recurso a la compra de armas y municiones en el extranjero no fue algo ocasional. Es paradigmática la situación de finales del siglo xvir y el momento de la Guerra de Sucesión, cuando la industria de armamento estaba bajo mínimos a causa de la crisis anterior, no del todo resuelta para $1700^{26}$. Pero después de ese conflicto el problema, aunque reducido, se mantuvo. Conocemos unas cuantas ocasiones en las que se compraron cañones de hierro: no menos de 12 veces, cuyas partidas suman un total de 8.385 piezas de diferentes calibres, solamente entre 1718 y $1778^{27}$. Pero no fueron solo cañones. También algunas de las citadas compras de cañones incluían compra de balería. Por otra parte, el problema de la calidad de las bombas españolas apareció en diversos momentos del siglo; en consecuencia, se compraron bombas a Francia por lo menos entre 1732 y $1736^{28}$, y después, entre 1766 y por lo menos 1770, según el asiento con el francés conde de Rostaing ${ }^{29}$.

Esas compras encierran una contradicción: el Estado no siempre promocionaba de manera suficiente al fabricante particular español, pero luego, cuando las necesidades arreciaban, se veía obligado a comprar fuera. Ahora, la pregunta desde el punto de vista del empresario es ¿qué podía hacer un empresario asentista, abastecedor del Estado, cuando no recibía pedidos? Dado que no existía un mercado privado de esos productos, ni exterior, porque el particular no podía exportar,

25. Por ejemplo, si un alto horno se había parado durante algunos años, era necesario acondicionarlo nuevamente, incluso reconstruirlo antes de ponerlo de nuevo en funcionamiento.

26. Ver Kamen, H.: La Guerra de Sucesión en España, 1700-1715. Grijalbo, Barcelona 1974; también CALVO POYATO, «La industria militar española».

27. Solo se llegaron a comprar, por razones variadas, 5089 piezas. No obstante, ese número es importante, ya que supone un 26,36 por ciento de la producción total de Liérganes y La Cavada. GONZÁLEZ ENCISO, A.: «Buying cannons outside: when, why, how many? The supplying of foreign iron cannons for the Spanish Navy in the Eighteenth Century» en HARDing, R. y SOLBES FerRI, S. (coords.): The Contractor State and its Implications, 1659-1815. Universidad de Las Palmas, Las Palmas de Gran Canaria, 2012, p. 149.

28. AGS, SG, 950.

29. AGS, Dirección General del Tesoro [en adelante DGT], inv. 25, leg. 17. 
la única solución que tenía era previa al problema y de alguna manera al margen de él. Se trataba de una desarrollar una estrategia empresarial que contemplara la diversificación para obviar la falta de pedidos; además, había que tratar que los recursos asignados a la fabricación de cañones, o municiones, pongamos por caso, no fueran excesivos en el conjunto del negocio del asentista, para evitar que lastraran negativamente el resto de las actividades.

Estos dos hechos -diversificación de esfuerzos productivos y limitación de las inversiones- están en la base de algunos de los problemas con los que se encontraban tanto los asentistas, como la Administración misma a la hora elegir a sus abastecedores o de recibir sus productos. El primero es que no bastaba cualquier asentista. Tenía que ser una persona de fuerte economía y seguridad, capaz de aguantar tanto las temporales ausencias de pedidos, como los retrasos, en las pagas, habituales por parte del Estado. Es razonable pensar que el rey tratara bien a estas personas, pero eso no siempre ocurría. Así, por ejemplo, el mantenimiento en los asientos de cañones de hierro de la familia Olivares está muy relacionado con los privilegios recibidos, probablemente la mejor manera, si no la única, de aguantar los problemas económicos derivados del aumento de los costes (por ejemplo los de alza de precio de los combustibles y materia prima, a causa de su transporte desde lugares cada vez más lejanos del edificio de la fábrica). Esos privilegios no se concedieron en el caso de Eugui, y aquí ocurrió que los asentistas fueron cambiando hasta que Mendinueta, a partir de 1735, consiguió mejorar algo la situación, lo que le permitió aguantar treinta años, no sin serios problemas en algunos momentos.

El segundo problema que se derivaba de las condiciones de explotación de estas empresas es que bajaba la calidad del producto. En 1760, a los pocos meses de llegar Carlos III al trono, y en medio de otra de las grandes urgencias militares, se planteó el problema de la calidad de los trabajos de Liérganes y La Cavada, más tarde se haría lo propio con los de Eugui. Parecía que, tras más de doce años de paz, con la consiguiente baja de la actividad, incluso con años improductivos, la técnica se había quedado obsoleta. Así pareció que lo atestiguaban dos experiencias negativas al respecto. Una de ellas fue la prueba realizada en La Cavada en 1760, de la que resultó la reprobación de más de un once por ciento de los cañones examinados ${ }^{30}$. Los porcentajes se reputaron como claramente mejorables y se insistió en la necesidad de reformar el sistema productivo. La otra experiencia, aparentemente de menor calibre, fue la consideración, por parte de algún militar francés de renombre, de que las bombas de Eugui empleadas en la intervención armada en Portugal, en 1762, eran de muy baja calidad. Aunque estas consideraciones

30. Helguera Quijada, J.: «De La Cavada a Trubia. Intervencionismo estatal y cambio tecnológico en las fundiciones de artillería del norte de España (1760-1800)» en OCAMPO SUÁREZ-VALDÉs, J.: Empresa y empresarios en el norte de España (Siglo XVIII). Trea, Oviedo, p. 158. 
no estaban exentas de prejuicios políticos e ideológicos ${ }^{31}$, demostraban, en todo caso, los problemas de calidad en la producción siderúrgica militar española en esos momentos.

Que las técnicas eran obsoletas fue algo fácil de demostrar y es evidente, para el historiador, con una leve comparación entre las técnicas productivas de vanguardia en otros lugares y las españolas de $1760^{32}$. Estaba claro que desde los años cuarenta, cuando tanto cañones, como balas y bombas, habían demostrado ser altamente eficaces, se había producido un parón tecnológico, al menos un retraso evidente. ¿La razón? No es fácil señalarlo, pero desde el punto de vista del empresario es bastante claro que una de las razones está en la falta de inversión en experimentar nuevas tecnologías, defecto que, en última instancia tiene una explicación económica. Se puede hacer alusión aquí a un comentario de Alcalá-Zamora sobre Jorge de Bande, segundo asentista de Liérganes entre 1629 y 1649, quien no solo hizo fortuna, sino que consiguió erigir varios establecimientos fabriles de éxito, siempre con pagos generosos del Estado. Cabría preguntarse, dice el citado autor, si Bande, sin su fuerte tasa de ganancias, habría podido ampliar sus instalaciones y poner su entusiasmo en ellas ${ }^{33}$. Lo contrario ocurrirá en el siglo XVIII con los sucesivos asentistas de Eugui.

No se puede decir que a los asentistas no les interesara la calidad. El Estado hacía pruebas de los productos recibidos y además, remitía, de vez en cuando, instrucciones sobre qué técnicas debían emplearse. Más de una vez envió también a las empresas inspectores técnicos y directores de fabricación que vigilaron estos asuntos. La falta de calidad repercutía en que el cliente no aprobaba los productos, que eran devueltos al fabricante y no pagados. Por lo tanto, si a pesar de todo no se invirtió en la mejora tecnológica no fue por falta de interés, sino por falta de seguridad económica. La mejora de la calidad era costosa, unos costes que no podía permitirse un empresario que se enfrentaba a una demanda pequeña y errática, y que además era pagado con retraso.

Que la Administración pagaba mal era algo que los propios gobernantes sabían de sobra. La prueba está en que cuando llegó el momento de las nacionalizaciones, a partir de los años sesenta, tanto en Liérganes, como en Eugui, las partidas que la Hacienda dedicó a estas empresas fueron claramente superiores a lo que se había estado gastando con los asentistas. Era evidente que el Estado no

31. También trataban de desprestigiar la gestión privada para justificar la estatalización de esas empresas, proceso que ya estaba en marcha en Liérganes, como queda dicho, o la concesión del asiento al militar francés, el conde de Rostaing, quien también era un fabricante, lo que ocurrió de modo temporal.

32. Helguera Quijada, J.: «De La Cavada a Trubia», et passim.

33. Alcala-ZamoRA, J.: Liérganes y La Cavada. Historia de los primeros altos hornos españoles (1622-1834). Estudio, Santander, 2004, p. 104. 
quería pagar si no ejercía un control total de la actividad. En todo caso, ese gasto no repercutió en una verdadera mejora de la calidad, porque como sabemos, los procesos tecnológicos no llegaron a renovarse de manera eficaz.

\section{LOS ASENTISTAS FABRICANTES DE CAÑONES DE HIERRO Y DE MUNICIONES}

Como señalamos al principio, en el mundo de los asientos existieron unas coordenadas generales, similares para todos, tanto a lo largo del tiempo como en relación con los problemas que las necesidades y los procedimientos generaron ${ }^{34}$. A su vez, las cuestiones específicas también acabaron produciendo una tipología variada; a ella intentaremos aproximarnos en los siguientes epígrafes. En este intento, el primer tipo de asentista que vamos a considerar es el del asentista fabricante, que se dio de modo particular, en el caso de los cañones de hierro y de las municiones.

Para satisfacer sus necesidades de contar con los productos citados, el Estado español eligió la opción de comprarlos en España mediante asiento. Ahora bien, los cañones y las municiones no se encuentran en cualquier mercado, además un particular no podía importarlos, luego si la Administración decidía comprar cañones de hierro a un asentista español, este no tenía más remedio que fabricarlos. Se trata de un asentista en tanto que contrata un servicio de abastecimiento con el Estado, pero que también se ve en la necesidad de fabricar el producto a proveer; de ahí que hablemos de un asentista fabricante. Fue el camino emprendido en 1622 en Liérganes, repetido en 1689 en Eugui y mantenido hasta los años sesenta del siglo xviII. A comienzos de este siglo Uztáriz se esforzó por demostrar que había abundancia de condiciones naturales en España que justificaban la opción de fabricar esos productos en casa $^{35}$, en vez de recurrir a la importación. Aunque ya hemos visto que la sola presencia de recursos naturales no era suficiente, estos asentistas cubrieron con satisfacción un largo período.

Este tipo de asentista apareció en España por primera vez en 1622, cuando el Estado aceptó la propuesta del fabricante de Lieja, Curcio, de fabricar cañones de hierro en España. Tal aceptación suponía elegir un modelo que no era el desarrollado

34. Ver, a modo de ejemplo comparativo, lo que ocurría con la pólvora en el siglo XVI. JIMÉNEZ Estrella, A.: «Asentistas militares y fraude en torno al abastecimiento de pólvora en el reino de Granada (siglo XVI)», Investigaciones Históricas, 30 (2010), pp. 11-30.

35. «Ya que la divina Providencia dotó a España... de todos los materiales necesarios para los armamentos... será acertado que agradecidos a este beneficio nos apliquemos a disfrutarle con las providencias correspondientes... por tener aseguradas estas provisiones dentro de los mismos dominios de su Majestad, sin estar pendientes del inconstante arbitrio de potencias extranjeras». UzTARIZ, J. de: Theorica y practica de Comercio y de Marina. Aguilar, Madrid, 1968, p. 217. 
hasta entonces en España ${ }^{36}$. Dos razones lo avalan. Por un lado está la ventaja que suponía el conocimiento técnico de los empresarios de Lieja, porque aquí la técnica juega un papel preponderante y entonces la forja de cañones de hierro ofrecía algunas dificultades ${ }^{37}$; por otro lado están los pocos caudales que entonces tenía el Estado. En consecuencia, se optó por la versión más barata para la Administración, considerada entonces también la más eficaz.

El modelo suponía otra característica del empresario, que podemos calificar como capitalista, si bien dentro de los esquemas del mercantilismo. Se trataba, fundamentalmente, de personas que tenían capitales y que, si bien eran conocedores de las cuestiones técnicas, tenían un amplio equipo humano a su servicio: dinero, división del trabajo y libertad de acción frente a organizaciones gremiales, son aspectos básicos del primer capitalismo ${ }^{38}$, y estos asentistas, como otros negociantes de la época ${ }^{39}$, son figura de ello. En todo caso, se trataba también de empresarios que trabajaban en un mercado restringido y con unas condiciones de trabajo privilegiadas; bien podrían llamarse, si no pareciera una contradicción, capitalistas privilegiados, pues tales eran las características del momento ${ }^{40}$.

Sobre esa base, el modelo establecido en Liérganes en el siglo Xvir fue el de una empresa fabril libre, cuyos dueños -empresarios-, esperaban firmar un contrato exclusivo con la Administración para la venta de sus productos. En realidad, un régimen de monopolio de facto $^{41}$. Como ha explicado Alcalá-Zamora, el primer empresario, Juan Curcio, prácticamente fracasó en la empresa, seguramente porque a la altura de 1622/1627 el Estado no estaba para muchas compras ${ }^{42}$, pero la actividad estaba iniciada. Más suerte tuvo su sucesor Jorge de Bande, que firmó en 1630 un asiento para fabricar 200 piezas de artillería, aún pequeñas, y cogió el momento de alza posterior a 1633, cuando de verdad se extendió la producción de Liérganes y luego de su anexo de La Cavada ${ }^{43}$. Bande demostraría ser un gran

36. Ver más abajo, el caso de los cañones de bronce, fabricados bajo otro modelo organizativo.

37. Se refiere a alguna de ellas, AlCalÁ-Zamora, J.: Liérganes y La Cavada, pp. 95-96.

38. GonzÁlez EnCiso, A.: El nacimiento del capitalismo en Europa. Eunate, Pamplona, 2011, pp. 19 y ss.

39. VÁzQuez de Prada, V.: «Los hombres de negocios de Burgos (s. XIV-XVI), ejemplo de mentalidad emprendedora», en KLEP, P. y VAN CAUwENBERGHE, E. (eds.): Entrepreneurship and the Transformation of the Economy (10th-20th Centuries). Essays in Honour of Herman Van der Wee. Leuven University Press, Lovaina, 1994, p. 476; GonZÁlez EnCISO, A.: «La cultura mercantil en la España Moderna y la mentalidad empresarial», Principe de Viana, 254 (2011), pp. 13-36.

40. Interesantes reflexiones al respecto en TORRES SÁNCHEZ, R. (ed.): Capitalismo mercantil en la España del siglo XVIII. EUNSA, Pamplona, 2000, «Presentación».

41. Para el término empresarios monopolistas, ver GonZÁlez EnCISO, A.: «La promoción industrial en la España Moderna: intervención pública e iniciativa privada» en RIBOT GARCíA, L .A. y Rosa, L. de (dirs.): Industria y Época Moderna. Actas, Madrid, 2000, pp. 15-46.

42. Recuérdese la bancarrota de 1627. Curcio falleció en 1628.

43. AlcalA-Zamora, J.: Liérganes y La Cavada, pp. 94 y ss. 
empresario, con iniciativa, dotes de buen gestor y capacidad para negociar con la Administración.

Los siguientes asentistas de Liérganes experimentaron una situación análoga, según los casos, a las de Juan Curcio y Jorge de Bande, es decir, poca ayuda y demanda estatales y bajo precio cuando la Hacienda tenía poco dinero (Curcio), mientras que ayudas, pedidos y precio pagado por la administración subieron cuando las necesidades se hicieron urgentes, o cuando existió una política continuada de producción y armamento (caso de Bande). Así, el asentista Diego de Noja (1649-1661) y luego los herederos de este y de Mariana Brito, viuda de Bande, seguirían peleando con la administración, salvo alguna excepción, a causa de unos precios que no siempre les favorecieron ${ }^{44}$. En cambio, el caso de Nicolás Xavier de Olivares, ya en el siglo XviI, fue algo distinto. Era nieto de Mariana Brito ${ }^{45}$, y desde 1715 -entonces aún menor de edad-ostentaría la propiedad de las fábricas y pactaría los asientos con la Administración. El período 1726-1737 coincidió no solo con un momento de auge de la Marina bajo los auspicios de Patiño, sino también con un momento de aumento del precio pagado por la Administración, pactado en los asientos ${ }^{46}$. De este modo, Nicolás Xavier de Olivares protagonizó una situación similar a la de Bande, beneficio personal y beneficio de una Administración que se decidió a invertir más en sus asentistas. Muerto Nicolás Xavier en 1737 , le sucedió su hijo Joaquín.

Ya se ve que en estos asuntos también juega un papel importante la relación familiar. Ciertamente en los orígenes, la propiedad de la fábrica de Liérganes se traspasó entre socios: Bande lo era de Curcio y además él mismo se elevó sobre otros socios que le habían acompañado al principio, pero también un sobrino suyo se encargaría de la fábrica establecida en 1642 en Corduente ${ }^{47}$. Por su parte, Diego de Noja había sido en realidad un competidor de Mariana de Brito, surgido del mundo de la misma Administración que controlaba las fábricas, y asentista de construcción de barcos él también ${ }^{48}$. Más tarde primarían los acuerdos y las herencias familiares: los herederos de Noja y los de Brito -los Olivares- se repartieron las dos fábricas ${ }^{49}$-tres mientras subsistió la de Corduente, no más allá de 1673-, hasta que finalmente Nicolás Xavier lo heredó todo, como lo haría luego su hijo Joaquín.

44. Idem, pp. 104-108.

45. Pero no de Bande. Los Olivares eran hijos de un primer matrimonio de Mariana de Brito con Juan Olivares, aunque al final heredaran a su padrastro, Bande.

46. Alcala-Zamora, J.: Liérganes y La Cavada, pp. 106, 110.

47. En Molina de Aragón. Idem, Altos hornos, pp. 125 y ss.

48. Idem, Liérganes y La Cavada, pp. 76-77.

49. «Los Noja y los Olivares, cada cual en su respectiva fábrica, continuaron hasta 1715 llevando “por mitades” oficiales el asiento». Idem, p. 108. 
Desde 1738, Joaquín de Olivares llevó adelante con éxito las empresas. En sus tres contratas, señala Alcalá-Zamora, siempre se adelantó en los plazos. Bien situado en la Corte, consiguió en 1742 el título de marqués de Villacastel y privilegios importantes en $1754-1755^{50}$. Esos reconocimientos eran fruto también de su postura favorable a ceder en algo, por ejemplo, aceptar una rebaja de precios y a la vez incrementar la producción. Pero fueron seguramente sus amplios privilegios los que complicarían la situación y el declive de la función del asentista.

Las ventajas que tenía le enfrentaron a la población local a causa de la rivalidad por la explotación de los montes. Como ya había ocurrido cuarenta años antes en el pleito entre Loperena y Aldaz, con los intereses de la población de Eugui de fondo, los privilegios del asentista se presentaban como una amenaza a los intereses locales. En Eugui, en 1719, se favoreció a los asentistas que decían representar también los intereses locales frente al empresario anterior, pero en el caso de Liérganes la Administración obró en un sentido diferente, pues en 1759 se buscaba ya la nacionalización de la empresa y la oposición local vino a ser un argumento usado, finalmente, para apoyar las decisiones que luego tomaría Carlos III. Villacastel murió en 1759, dejando una amplia fortuna, una producción en alza, y no pocos problemas, entre ellos los pleitos que sus herederos no pudieron o no quisieron gestionar en defensa de la propiedad ${ }^{51}$.

En 1759, por lo tanto, asistimos en Liérganes al comienzo del fin de una estirpe empresarial cuya fortuna se gestó, de la mano de Curcio, empresario en Lieja, y de Bande -el luxenburgués-, su socio en España, a partir de la propia actividad industrial. Con independencia de la posible presencia de algún capital mercantil, lo que está claro es que Bande hizo un gran negocio con las fábricas, una fortuna que pudo legar a los hijos de su mujer, los Olivares. ¿Tenían estos alguna fortuna por parte de su padre Juan? Aunque no lo sabemos, parece claro que la herencia siderúrgica, que ellos mismos aumentarían, era suficientemente fuerte como para ser la protagonista. Así pues, desde 1650 hasta 1760 hay una línea continuada de empresa familiar industrial, a veces con otros partícipes, que explota su fábrica gracias a los asientos con la Administración, y que se enriquece con ese negocio fabril.

La fábrica de Eugui es la otra empresa siderúrgica, bastante significativa, que nace en el siglo xvi gracias a la iniciativa de un empresario, José de Aldaz, luego marqués de Monte Real, que basa sus posibilidades en los asientos firmados con la Administración para el abastecimiento de un determinado género, municiones en concreto. Es un caso ligeramente distinto de Liérganes. Aldaz era un comerciante,

50. Ver AGS, SG, 7904.

51. Seguramente, estos herederos deseaban vender la empresa al ver el desarrollo de los acontecimientos. Alcalá-Zamora, J.: Liérganes y La Cavada, pp. 112-114. 
hijo de comerciante, que en un momento determinado sintió interés por la inversión en una fábrica de municiones. Probablemente la oportunidad apareció con el aumento de la actividad bélica contra Luis XIV ${ }^{52}$, que evidenció precisamente, la falta de aquellos géneros. Si en Liérganes había que aumentar la producción de cañones, no había mucho tiempo para dedicarse también a las municiones; estas deberían procurarse en otra parte. De todos modos, también aquí aparece un empresario -si bien claramente de origen mercantil-, que ve la oportunidad, que compra la empresa a la Administración e invierte en ella a cambio de los beneficios esperados de un acuerdo con esa misma Administración.

Una peculiaridad de Eugui es que aquí la empresa ya existía desde hacía tiempo y era del Estado. En realidad, era la empresa siderúrgica más veterana de España, pues se puede datar su presencia como Armería Real desde 1534, pero su actividad anterior había sido diferente, orientada a la fabricación de cascos y armaduras $^{53}$. En 1689 la fábrica estaba abandonada, una situación en la que podrían haber incidido tanto la relativa obsolescencia de sus productos, como la falta de dinero de la Hacienda. Aldaz propuso comprar la fábrica al rey y transformarla en una moderna siderurgia para la fabricación de municiones. Si la oportunidad de relanzar Eugui y reorientar su producción, fue la guerra, lo que no sabemos con exactitud es por qué se decidió hacerlo por vía de asiento con un particular. Lo más probable es que los dineros del comerciante (unos 80.000 reales, más diversas provisiones $)^{54}$, fueron más que suficientes para resolver con sentido práctico, lo que de otro modo parecía difícil para una Hacienda exhausta.

Aldaz demostró que esa nueva actividad también podía ser negocio; de hecho, en 1702 ampliaba su empresa - «para mayor abundancia», decía ${ }^{55}$ - y mejoró la producción ${ }^{56}$. La fábrica llegaría a ser, en sus palabras, el «nervio principal» de su hacienda ${ }^{57}$. Pero esa misma importancia fue la causa de que despertara el interés de un grupo mercantil rival, el de Loperena, que acabó por obtener del rey tanto la propiedad, como la concesión del asiento en $1719^{58}$. Loperena se aprovechó de los litigios de Aldaz con el lugar de Eugui por el aprovechamiento

52. Idem, Altos hornos, p. 357.

53. Un resumen de la historia de Eugui, anterior a 1689, en RABANAL Yus, A.: Las Reales Fábricas de Eugui y Orbaiceta. Institución Príncipe de Viana, Pamplona, 1987.

54. Andueza Unanua, P.: «De padre cerero a hijo marqués: José de Aldaz y Aguirre, marqués de Monte Real», en GonZÁlez EncISO, A. (ed.): Navarros en la Monarquia española en el siglo XVIII. EUNSA, Pamplona, 2007, p. 100.

55. HeRnÁNDEZ EsCaYOla, C.: Negocio y servicio: Finanzas públicas y hombres de negocios en Navarra en la primera mitad del siglo XVIII. EUNSA, Pamplona, 2004, p. 248, n. 115.

56. De hecho, en Eugi se instalarían los segundos altos hornos de España, después de los de Liérganes y La Cavada. Alcala-Zamora, J.: Altos hornos, p. 357.

57. Aundueza Unanua, P.: «De padre cerero a hijo marqués», p. 104.

58. GonZÁlez EnCISO, A.: «Empresarios navarros en la industria», pp. 168-169 y 181. 
de los montes. Todo desembocó en un pleito en el que Aldaz perdió su asiento y su empresa. Pero en realidad los problemas de Aldaz estuvieron relacionados, sobre todo, con la actitud de la Administración. Hay una contradicción entre el comportamiento del asentista, que cumple con sus entregas de material en los plazos pactados, y el de la Hacienda, que no paga con puntualidad y que, además, trata de bajar los precios en cada renovación del asiento ${ }^{59}$. Luego aparecieron las reclamaciones del lugar de Eugui. En todo caso, la victoria de Loperena y Compañía en 1719 se basó no solo en esta debilidad de Aldaz, sino en la argucia de hacer ver que ellos representaban los intereses del lugar de Eugui, enfrentado con el empresario por el problema de los cortes de madera para la combustión de los hornos.

Loperena y Compañía eran también comerciantes que eventualmente invirtieron en una empresa fabril en la espera de conseguir beneficios. Pero ellos también se encontrarían con problemas. Algunos vinieron de Aldaz, quien interpuso un pleito de reclamación que acabaría devolviendo definitivamente a su viuda la propiedad en 1730; no obstante, el rey se reservó el derecho a conceder el asiento y Loperena y Compañía siguieron con él, si bien a partir de entonces hubo que pagar una cantidad, en razón de alquiler, a la propietaria de las instalaciones, la marquesa viuda de Monte Real ${ }^{60}$. Pero pleitos aparte, tampoco lo tuvieron fácil Loperena y Compañía, que se enfrentaron, primero, a la guerra de 1719, que afectó a la zona y produjo destrucciones en la fábrica, y luego a las rebajas de precios que seguía imponiendo la Administración; finalmente, los problemas les llegaron por el surgimiento de la competencia en las fábricas de Asura e Iturbieta, lo que quitó a Loperena el monopolio que de facto tenía en las municiones ${ }^{61}$.

La aparición de esta competencia venía a demostrar nuevamente la importancia de la política, en este caso la que proporcionaba la influencia en la Corte. A lo mejor Loperena y sus compañeros habían hecho sentir esa influencia al conseguir la empresa en 1719, pero más tarde las cosas se estaban volviendo del revés y eran Arizcun y Mendinueta, relacionados con Aldaz, los que parecían ganar la baza. En torno a 1725, en medio de un momento de paz, ya se había producido un parón productivo en Eugui, que planteó dudas en la Administración sobre qué partido tomar. Luego, la competencia instalaría sus empresas a partir de 1727, otra vez con rumores de guerra al fondo. Es posible que el aumento de necesidades que trajo consigo el impulso dado a la Marina por Patiño acabara salvando a Loperena y compañeros, a quienes se dejó continuar con el asiento, dejando Asura e

59. Hernández Escayola, C.: Negocio y servicio, p. 250.

60. Andueza Unanua, P.: «De padre cerero a hijo marqués», pp. 106-108.

61. GonZÁlez EnCISO, A.: «Empresarios navarros en la industria», pp. 183-185. 
Iturbieta como complementarias; pero el esfuerzo resultó casi baldío. A duras penas Loperena terminó su asiento, que ya no renovaría ${ }^{62}$.

La suerte estaba echada y en 1735 quien firmó el asiento de Eugui fue Francisco Mendinueta. Es significativo que haya coincidencias, aunque no del todo exactas, primero entre los años de comienzo de los problemas de Loperena y el establecimiento de Asura e Iturbieta, y luego entre el final de Loperena, el triunfo de Mendinueta en Eugui y la desaparición de las otras dos empresas de este con Arizcun. Está claro que Mendinueta, de la mano de Arizcun, hizo una doble competencia a Loperena, tanto en la fabricación, como en la influencia en la Administración. No solo consiguió asientos para sus dos pequeñas fábricas, que claramente perjudicaban a Loperena, sino que luego vencería al desplazar del asiento de Eugui a los anteriores asentistas. Cuando Mendinueta consiguió el contrato de Eugui, la fabricación en Asura e Iturbieta ya no interesaba a nadie y se cesó en su producción.

La razón por la que Mendinueta decidió concentrar su esfuerzo fabril en Eugui no se expresó con toda claridad, pero se puede presuponer que Eugui tenía mejores posibilidades para mejorar la calidad y aumentar la producción que Asura o Iturbieta. Además, estas fábricas estaban orientadas hacia la vertiente norte, hacia Guipúzcoa, lo que condicionaba que el transporte de su producción encontrara mejor la salida hacia el Cantábrico. De hecho, la producción de estas fábricas se enviaba a un almacén en Rentería, buscando la salida marítima por Pasajes ${ }^{63}$. Esta condición seguía inalterada años después, aunque daba lugar a una situación tan incómoda que la hizo obsoleta, porque los momentos de guerra hacían del Cantábrico una salida complicada ${ }^{64}$, por lo que se volvió a potenciar la tradicional salida de las municiones navarras hacia el Ebro, camino del Mediterráneo, la vía que siempre se tuvo en cuenta para la producción de Eugui ${ }^{65}$. En esas condiciones tampoco interesaba continuar, ya en los años treinta con la producción de Asura, que planteaba problemas extra de transporte.

62. No conseguirían el finiquito hasta 1749 , lo que evidencia los problemas para aclarar las cuentas. AGS, SG, 439.

63. Ya lo preveía así el asiento de Norberto Arizcun, de 1723, que luego heredaría y prorrogaría su sobrino Miguel. Archivo General de Navarra [en adelante AGN], Artillería y Fábricas de Guerra [en adelante AF], caja 1, carpeta 6.

64. El acuerdo de Asura se renovó en 1728, pero años después, había de hecho muchas municiones prácticamente abandonadas en Rentería. Ver un expediente sobre balería, sin fecha, ni firma, seguramente de los años cuarenta, en AGS, SM, 660.

65. De hecho, los asentistas de Eugui se quejaron en 1728 de que se pretendiera que enviaran las municiones hacia San Sebastián, cuando su asiento acordaba entregarlas en Pamplona. Los asentistas del lugar de Eugui a Castelar, Madrid, 18 de junio de 1728, AGS, SG Suplemento, 8. Algunas anotaciones sobre los problemas de la salida de municiones por el Cantábrico en GonZÁLEZ ENCISO, A.: «La renovación del asiento de transporte de municiones y armas en 1793 y el protagonismo de una familia navarra», en Memoria y Civilización, 15 (2012), pp. 62-63. 
Tampoco Mendinueta era un fabricante, ni siquiera un comerciante como Aldaz; era más bien un hombre de negocios, un asentista. Aunque hijo de comerciante, su marcha a la Corte confirmó su conexión con el mundo de los arrendatarios de rentas y asentistas navarros, el mundo de Juan de Goyeneche, con quien estaba emparentado y que acabaría permitiéndole el acceso a determinados asientos importantes ${ }^{66}$. Su orientación fabril le vino por sus relaciones con los Arizcun, que habían invertido también en el negocio de las ferrerías ${ }^{67}$. Se supone que el apoyo de Arizcun le valió los cuatro importantes asientos que Mendinueta consiguió al principio de su carrera de asentista: primero el de Asura, desde 1723, con Arizcun; luego, él aparentemente solo, los de Iturbieta, en 1726, Eugui, en 1735 y el de la conducción de armas y municiones, de $1737^{68}$. Así pues, Mendinueta sería en Eugui un asentista fabricante, no le quedaba más remedio, pero su figura como asentista encaja más bien en la de un negociante que gestiona asientos variados. Es de hecho, el gran asentista de su época.

En el asiento de Eugui de 1735, Mendinueta consiguió que se volviera a aumentar el precio pagado por el Estado, una de las principales razones, según el mismo Mendinueta, del fracaso de Loperen ${ }^{69}$. Pero eso fue solamente el comienzo. Después, Mendinueta tendría los mismos problemas que los anteriores asentistas respecto a la política errática del Estado, que incluía nuevas rebajas de precios en los nuevos asientos, además retrasos en los pagos, o bien, pedidos fuera del asiento para atender urgencias, que luego también se pagaban mal. Los asientos de Mendinueta en Eugui, que duraron hasta 1765, tienen una historia de éxito y problemas a tenor también de las oscilaciones de las necesidades militares, según la inminencia de las guerras. Los dos primeros asientos, los de 1735 y 1745, se firmaron en momentos de guerra, pero su desarrollo atravesó los años de paz intermedios entre cada conflicto, lo que causó numerosos quebraderos de cabeza al asentista. El último asiento, firmado en 1755, tuvo momentos de gloria más breves y un final más abrupto ${ }^{70}$.

66. Aquerreta, S. (coord.): Francisco Mendinueta: finanzas y mecenazgo en la España del siglo XVIII. EUNSA, Pamplona, 2002; Torres SÁNCHEZ, R.: «El gran negocio de la época, la provisión de víveres al ejército por Francisco Mendinueta (1744-1763)» en AQUERRETA, S. (coord.): Francisco de Mendinueta, pp. 101-134.

67. AquerRETA, S.: «La casa de Arizcun, 1725-1742: Las estrategias financieras de un hombre de negocios en el Madrid de la Ilustración», en Ferrer Benimeli, J. A. (dir.): El conde de Aranda y su tiempo. Institución Fernando el Católico, Zaragoza, 2000, pp. 659-678.

68. Aquerreta, S.: «"De su cuenta y riesgo y por vía de asiento”. Trayectoria y negocios de Francisco Mendinueta (1744-1763)» en AqueRRETA, S. (coord.): Francisco de Mendinueta, pp. 88-89.

69. Consiguió volver a los precios de 1717, mayores que los que se habían pagado a Loperena. El asiento en AGN, AF, caja 1, carpeta 8. Una copia, con todas las condiciones de los allanamientos incluidas, en AGS, SM, 660.

70. GonZÁlez EnCiso, A.: «Empresarios navarros en la industria», pp. 188 y ss. 
Mendinueta fue también protagonista en las otras dos fundiciones de balería mencionadas. Lo fue desde el principio en Iturbieta, pero también lo fue de algún modo en Asura, la fábrica de su primo Miguel Arizcun. Por ejemplo, para que Asura cumpliera su asiento de 1729 , se convino que «en esta fábrica de Iturbieta se fundiese la mitad [de una cantidad] de cuenta de don Miguel Arizcun, que estaba encargado de fundirlas en su fábrica de Asura» ${ }^{71}$; por otra parte, cuando terminó el asiento de Iturbieta en 1737, Mendinueta y Arizcun fueron citados juntos, al parecer sin hacer distinción entre ambos, aunque luego se distinguiera cada asiento en concreto. Se ve que aquí jugaba el parentesco, que les hacía partícipes de ambas empresas, aunque figurara uno de ellos en cada caso, sin que sea fácil hacer la distinción real de la participación de cada uno ${ }^{72}$.

Lo que sí parece es que se trata de dos fortunas industriales que evolucionaron, como tales, en sentido contrario: primero Arizcun ayudó a Mendinueta a entrar en el negocio de las ferrerías; años después la historia sería la inversa. Durante los años treinta Mendinueta estaba más consolidado en Eugui e Iturbieta, mientras que Arizcun se habría especializado más en la provisión de víveres a la Armada y en otros negocios con el Estado en los que aumentó su presencia durante esos años ${ }^{73}$ ¿ ¿Cabe pensar que en el éxito de Mendinueta influyeron las posibles ganancias en Eugui? Cabe pensarlo, desde luego, y en este sentido la parte fabril del asentista tomaría una mayor relevancia, al revés de lo que estaba ocurriendo con su primo, al menos en los años citados. Hay que tener en cuenta, de todos modos, que Mendinueta también tenía otros negocios, además de las fundiciones, como por ejemplo el de la conducción de armas y municiones. Por otra parte, desde 1744 Mendinueta conseguiría también el asiento general de víveres para el ejército, entonces firmado ${ }^{74}$, que a la larga sería el que le proporcionaría mayores beneficios.

En definitiva, si en Liérganes vimos una estirpe familiar-de padres a hijos-que se enriqueció con la fábrica, en Eugui vemos a varios asentistas cuyas respectivas riquezas provenían de fuentes más variadas. En todo caso, también estos alcanzaron su posición gracias a apoyos familiares que en parte tenían una base industrial, y a los apoyos en la Corte. Los Olivares se nos muestran solo como fabricantes, con independencia de que pudieran haber comprado otros bienes productivos, sobre

71. AGS, SG, 438.

72. Para apreciar la mezcla de los negocios familiares resulta curioso ver que cuando Arizcun fue ennoblecido en 1741, lo fue como marqués de Iturbieta, que era el nombre de la ferrería que parecía haber regentado siempre Mendinueta.

73. Su tío Norberto había conseguido el asiento de la provisión de víveres en 1722, y Miguel mantendría este asiento en su poder muchos años más. TORRES SÁNCHEZ, R.: «Los navarros en la provisión de víveres», pp. 235 y 244-245.

74. TORRES SÁNCHEZ, R.: «El gran negocio de la época». 
todo tierras; en cuanto a los fabricantes de Eugui, Aldaz y Loperena, habían sido más bien, comerciantes y Mendinueta sería, sobre todo, un negociante. Lo mismo podríamos decir de su pariente y socio Arizcun. Ambos participaban también en el negocio financiero de los arrendamientos de rentas. En cualquier caso, todos ellos aparecen como asentistas fabricantes en lo que a nosotros respecta, pues, con independencia de que tuvieran más o menos diversificados sus negocios y esfuerzos, necesitaron encargarse directamente de la fabricación de las municiones que debían entregar.

Aunque haya que dar un salto de casi medio siglo, período en el que las circunstancias del sector cambiaron drásticamente, merece la pena situarse en 1794, otro momento de cambio, cuando Antonio Raimundo Ibáñez dé comienzo al primer alto horno de Sargadelos que trabajaría para el ejército. Se trata, también en este caso, de un particular que firma un asiento con el Estado para el abastecimiento de municiones; pero la historia de Antonio Raimundo Ibáñez tiene también sus aspectos diferenciales respecto a los ejemplos ya vistos. Ibáñez llegó al negocio férrico después de una larga carrera de unos veinte años al menos, que le había consolidado como un importante comerciante mayorista de Galicia ${ }^{75}$. En 1787 su carrera protagonizó un cambio y Raimundo Ibáñez se interesó por la industria; primero por la del lino, en la que puso mucho empeño, luego por las ferrerías.

El cambio al sector férrico pudo haberse basado en la buena lectura de la coyuntura de los negocios en Galicia: la industria del lino empezaba a tener problemas y en cambio, se notaba el auge de la demanda de productos férricos por parte de la Marina, a la zona de Asturias y Galicia, en perjuicio de la industria vasca. Dentro de Galicia, Ribadeo era una de las zonas de mayor tradición siderúrgica ${ }^{76}$. En un ambiente cada vez más propicio a la expansión de la industria férrica, Raimundo Ibáñez se decidió en 1788 a entrar en la fabricación de herrajes para la Marina. Además de otros negocios con sus socios, Ibáñez estableció con José de Andrés García, una ferrería y un horno de fundición en Sargadelos, en 1791. Tres años después, el alto horno no solo tendría todo el protagonismo, sino que se había cambiado su objetivo de producción: de las ollas de Burdeos, a la munición para el Ejército. De hecho, aunque el asiento no se firmara hasta 1796, Sargadelos está produciendo para el Ejército desde 1794, cuando se destruyeron las fábricas del Pirineo.

La empresa funcionó con normalidad hasta 1808, lo que contribuyó también a solucionar los problemas financieros y empresariales de su propietario ${ }^{77}$. Así

75. En este caso me limito a seguir a Carmona Badía, X.: «Antonio Raimundo Ibáñez, un empresario en el filo de dos épocas», en OCAMPO SuÁREZ-VALDÉs, J.: Empresas y empresarios, pp. 69-90. Allí se cita otra bibliografía también relevante sobre Sargadelos.

76. Idem, p. 77.

77. Idem, pp. $79-81$. 
pues, a finales de siglo, y dado que todas las empresas abastecedoras de municiones para el Ejército, nacionalizadas en tiempos de Carlos III, habían desaparecido, de nuevo un particular pudo salvar la demanda estatal de municiones y a la vez hacer un buen negocio. Durante esos años, Raimundo Ibáñez fue, como los anteriores, un asentista fabricante, propietario de su empresa, ligado al Estado por un asiento de provisión de municiones.

Cabría añadirse a todo lo dicho, que los asentistas no son los únicos protagonistas en la cabeza directiva de sus empresas. Por ejemplo, José de Aldaz tuvo un administrador, Adán J. Maculain, nombrado a veces factor en los documentos, y que en ocasiones figura al frente del asiento en nombre de su jefe. También Mendinueta tuvo administradores en Eugui que se encargaban directamente de la gestión, pues él residía en Madrid. Del mismo modo, en algunos momentos la Administración nombró un llamado Director para estas empresas, que en realidad era un supervisor técnico, un militar que velaba por que se cumplieran las especificaciones técnicas requeridas. Por supuesto, están los fundidores jefes, los técnicos que conocen los procesos de fabricación y dirigen a los operarios. Pero en cualquier caso, el protagonista del asiento, quien asume la responsabilidad, el verdadero asentista -el empresario, por lo tanto-, es siempre el negociante de turno; las demás figuras quedan en la penumbra y rara vez son mencionadas.

\section{LOS ASENTISTAS FUNDIDORES DE CAÑONES DE BRONCE EN EMPRESAS DEL REY}

En contraste con lo que se acaba de decir, en las empresas de cañones de bronce la figura del fundidor tiene un protagonismo mucho más evidente, pues es él quien aparece como encargado de la empresa, sea privada o de la Administración. Además, según su tradición, los fundidores en bronce firmaban cada una de sus piezas. En todo caso, en este sector la Administración desarrolló ya desde el siglo XVI diversos modos de gestión. Inicialmente, desde fines del siglo Xv y comienzos del xvi, la tarea de fundición de armas fue una actividad libre en la que el fundidor ajustaba su trabajo con el cliente ${ }^{78}$. Es posible que para trabajos pequeños el mismo fundidor actuara como empresario; pero seguramente, cuando el negocio era mayor, habría un comerciante que contratara con uno o varios fundidores. A partir de algún momento durante el siglo xvi, el mismo rey acabó contratando directamente con los fundidores para poder aumentar, y controlar mejor, su producción de cañones de bronce, como seguramente ocurrió en las fundiciones de Barcelona y de Málaga ${ }^{79}$. Un modelo similar se había seguido ya en

78. SuÁrez MenÉndeZ, R.: «La industria militar», p. 218.

79. Idem, p. 219. 
algunas armerías, como la de Eugui entonces, que fabricaba cascos y armaduras, y se consideraba Armería Real, que en este caso significaba, propiedad del rey.

Aunque la bibliografía no lo deja claro, es bastante probable que en estas empresas el Estado dirigiera la gestión y fuera el propietario de edificios y bienes de equipo. Pero la crisis económica del siglo xvir y la falta de dinero de la Hacienda hicieron modificar la gestión y de la acción estatal directa se pasó a un sistema de asientos ${ }^{80}$, según el cual los fundidores contratados tuvieron más protagonismo y libertad. El fundidor aparece de nuevo con más claridad como un empresario que, si bien trabaja en unas dependencias que no son suyas, tiene que gestionar por su cuenta el taller y afrontar algunos costes empresariales antes de entregar sus productos al Estado, con el que tiene un contrato de provisión, un asiento. También en este caso se trata de actividades exclusivistas, para un solo cliente estatal.

Parece que de todas las fábricas anteriores, la única que sobrevivió en el siglo xvi fue la de Sevilla ${ }^{81}$. Había sido creada en 1565, si bien aquí los propietarios y gestores fueron desde el principio fabricantes libres, fundidores ellos mismos a veces, que se asociaban con otros fundidores para poder cumplir con el asiento hecho con el rey. Es el caso de Bambel y Ballesteros. El Estado compró la empresa en 1634. Tal parece que en un momento de debilidad hacendística, el Estado decidió concentrar esfuerzos y asegurar el control; por eso compró, pero a la vez encomendó la gestión a los mismos asentistas particulares que habían regentado la empresa ${ }^{82}$. De esa manera se podía asegurar la continuidad de la calidad sin hacer mayores desembolsos.

Tal parece que en ese momento la supervisión no era grande y el asentista trabajaba con bastante libertad, si bien supuestamente con escasos beneficios en comparación, por ejemplo, con Liérganes ${ }^{83}$. Esta comparación nos obliga a señalar, de todos modos, que en la empresa cántabra los asentistas eran propietarios de unas instalaciones cuyos costes de establecimiento y previsible amortización tuvieron que soportar. Esto no ocurría con los asentistas de Sevilla, contratados como tales, para trabajar en una empresa cuyas instalaciones había comprado la Administración. De ahí seguramente, como señala Aguilar Escobar, derive la diferencia de precios que se estilaban en una y otra empresa.

El asentista Bambel trabajó también sometido a los típicos retrasos en los pagos, tendría problemas con las entregas y fue cesado como asentista en 1639. Durante

80. Aguilar Escobar, A.: pp. 55 y ss., pp. 70-71.

81. Seguramente seguía también la de Barcelona, pero no hay noticias de ella en el siglo XVII.

82. Aguilar Escobar, A.: Cañones de bronce, p. 72.

83. El juicio se hace por comparación entre los precios por quintal fundido que cobraba el asentista de Sevilla y lo que cobraba el de Liérganes, aunque los productos y circunstancias fueran diferentes. También por las reiteradas quejas de los siguientes asentistas, los Habet, sobre la cuestión monetaria. Idem, p. 74. 
diez años se encargaría de la empresa su fundidor y socio, Ballesteros. Tras un breve momento de confusión, en 1650 se firmó nuevo asiento con los Habet, una familia de comerciantes alemanes afincados en Sevilla, que disfrutarían el asiento hasta $1717^{84}$. Una de las ventajas de esta familia es que conocían el comercio del cobre, cuyo abastecimiento había sido otro de los problemas que la empresa había tenido hasta entonces. Pero entendían también el oficio de la fundición. Aguilar Escobar no menciona que con los Habet hubiera ningún fundidor (fundidor y empresario, como de alguna manera había sido Ballesteros con Bambel); es más, el autor emplea indistintamente los términos asentista y fundidor para referirse a los Habet y sus descendientes. De este modo, los Habet serían comerciantes y fabricantes a la vez, dentro del mismo sector metalúrgico en el que eran especialistas.

En 1717 cambiaría este modelo y la empresa pasaría a gestionarse con una mayor presencia de la Administración mediante un sistema que Aguilar Escobar llama mixto: la propiedad sigue siendo estatal, pero ahora los fundidores trabajan a las órdenes de un coronel de Artillería, director, y un contralor, más todo un equipo directivo militar que lleva los asuntos económicos y de hecho, la gestión de la empresa; hay, pues, un control e intervención totales por parte de la Secretaría de Guerra. Las razones de este cambio están no solo en el mayor deseo de control a los asentistas, sino en las necesidades de adaptarse a las reformas militares, en concreto a las derivadas de la creación del Cuerpo de Artillería en $1707^{85}$.

En este escenario, las competencias del asentista se limitan a lo estrictamente técnico, mientras que en lo demás estará a las órdenes del director de la fábrica. Ahora ni siquiera tenían que financiar la compra de la materia prima ${ }^{86}$. A veces se encargan también del pago de los operarios, por lo que es como si regentasen, en parte, un taller de fundición. Aunque siguen con sus asientos, son propiamente maestros fundidores que contratan su trabajo con el rey, dentro de la empresa militar. Su función se limitaría aún más en años posteriores incluso en lo estrictamente técnico, a medida que el cuerpo de Artillería fue enviando a la fábrica oficiales que se consideraban expertos en fundición y que intervinieron de manera muy directa en los procesos técnicos y en sus posibles transformaciones. Este modelo durará hasta que en 1767 se pase a la gestión directa por parte de la Administración ${ }^{87}$.

En la fábrica de cañones de Sevilla, en definitiva, se desarrollan unas formas empresariales diferentes a las de las fundiciones de hierro colado. En ellas se enlaza

84. Idem, p. 79.

85. Idem, p. $117-118$ y ss.

86. Aunque a veces tenían que adelantar el valor de su compra, que luego se les reembolsaba tarde. Idem, p. 125.

87. Idem, p. 143. 
con la tradición de las fundiciones reales de bronce, en las que, desde el siglo XvII, a veces antes, el protagonismo del fundidor es compatible con la propiedad e incluso gestión, del Estado.

En todo caso, también en estos fundidores operó la clave familiar a la hora de la transmisión de los asientos. En el siglo xvi dominó en Sevilla la familia de Enrique Habet, que lo seguiría haciendo, a pesar del cambio de condiciones de gestión, desde 1717: hasta los años cuarenta los fundidores asentistas serán descendientes de Habet, y luego de Matías Solano, un maestro que había trabajado en Valencia y Pamplona, a quien seguirían su hijo y su nieto. A partir de 1742, Juan Solano y su hijo José -desde 1757-, serán los últimos asentistas fundidores de la empresa ${ }^{88}$.

La otra empresa artillera importante del siglo xviI fue la fábrica de cañones de bronce de Barcelona. Como hemos visto, sabemos que pudo haber existido una actividad de fundición de cañones en el siglo xvi, pero no sabemos mucho más hasta principios del siglo xviII, con seguridad desde 1719, cuando se desarrolla la empresa en el seno de las antiguas atarazanas. Suponemos que tenía una organización similar a la de Sevilla: una fábrica perteneciente al Estado y gestionada por sus oficiales, pero cuyas fundiciones estaban a cargo de asentistas fundidores. Conocemos los nombres de los fundidores de la primera mitad del siglo xviII: Pere Ribot, Francesc Mir y Joseph Barnaola, que, al menos hasta 1765, funcionaron con el sistema de asientos ${ }^{89}$, suponemos similar al de Sevilla. En conjunto la fábrica de Barcelona sería menos importante que la de Sevilla, cuya producción complementó 90 .

Aunque de modo ocasional, también se fabricaron cañones de bronce en Pamplona y Valencia, en algunos momentos de comienzos del siglo xviII. Conocemos la existencia de estas fábricas sobre todo porque aparecen en la documentación de $\operatorname{archivo}^{91}$, pero no parece que hayan sido estudiadas. Por lo que sabemos, la forma empresarial habría sido similar a las de Sevilla y Barcelona en el siglo xviII, es decir, fundidores al servicio de una empresa instalada por la Administración. En realidad, parecen haber respondido más bien al modelo inicial, de en torno a 1500, cuando aún no se consideraba un lugar fijo de fundición y lo más económico era aportar los recursos y ejecutar los preparativos en cualquier lugar más o menos apropiado. Como señala Suárez Menéndez para aquellas primeras fundiciones de artillería, «se verificaban en el paraje donde habían de servir o permanecer las piezas ${ }^{92}$. Lo que quiero resaltar es la característica circunstancial de estas empresas

88. Idem, p. 137.

89. MarTí, R.: Cataluña armería de los Borbones, p. 66.

90. Aguilar Escobar, A.: Cañones de bronce, p. 50.

91. Ver Archivo General de Simancas, Secretaría de Guerra.

92. SuÁreZ MenénDEZ, R.: «La industria militar», p. 218. 
que no crecieron, no encontraron un asentamiento fijo y ocuparon poco espacio en el lugar donde comenzaron.

Su actividad fue breve. En un documento de la Secretaría de Guerra de 1740, donde se hacen consideraciones ante las fuertes necesidades de cañones, se dice, entre otras cosas, que para aliviar tales necesidades se podría recurrir a «reactivar» las fábricas de Pamplona y de Valencia, lo que nos confirma que su actividad había cesado antes de esa fecha. Aparte de la documentación sin estudiar, las pocas y breves noticias de ellas se refieren, por ejemplo, a que en 1717 se ordenó la fabricación en Pamplona de sesenta cañones de bronce, se supone que porque era más sencillo y barato tenerlos de ese modo cerca de la frontera francesa, que no tener que enviarlos allí desde Sevilla ${ }^{93}$, o bien al hecho ya mencionado de que Matías Solano, antiguo fundidor en Valencia y en Pamplona, pasó a Sevilla en $1728^{94}$.

\section{LAS ARMAS LIGERAS. EL GREMIO FABRICANTE Y EL COMERCIANTE ASENTISTA}

Si los cañones y municiones tenían su problemática fabril, las armas ligeras, en concreto los fusiles y las pistolas, tenían las suyas. En este caso no se trataba de la necesidad de grandes hornos de fundición y muchos gastos de inversión, sino al contrario, de ferrerías pequeñas, pero cuyo producto debía ser luego trabajado por manos expertas. Los fabricantes de pistolas y fusiles se consideran, sobre todo, artesanos y como tantos de su clase, están agremiados. Más allá del taller personal de cada maestro, está el colectivo gremial que, en este caso, se tenía que coordinar de alguna manera para poder satisfacer las necesidades de la Administración.

Desde el siglo xvi funcionaban en Guipúzcoa diversos centros de fabricación de armas ligeras, de organización gremial. Ese trabajo tenía que ser controlado y así aparece en 1576 la figura del veedor, nombrado por el rey. El Estado podía de este modo controlar la producción de todos los talleres, así como su calidad. Controlaba, además, la venta del producto, para asegurar que no fuera a particulares mientras el Estado no estuviere abastecido ${ }^{95}$. Esos cometidos se realizaban desde la Casa Real de Placencia, que funcionaba como centro administrativo. El conjunto, sin embargo, llevaba el nombre de Reales Fábricas, por los privilegios que gozaba. Poco a poco, el control administrativo fue creciendo, a la vez que se perdió la libertad de mercado en la medida en que durante algún tiempo

93. De la Vega Viguera, E.: Sevilla y la Real Fundición, p. 102. Ver también la noticia que da Gil Ossorio de que se empezó la fabricación en Pamplona en 1717 para poder atender el frente norte. Gil Ossorio, F.: Organización de la artillería española en el siglo XVIII. 1, la época de los artilleros empíricos de las guerras de Felipe V. Servicio Histórico Militar, Madrid, 1981, pp. 120-121. Sabemos que se llegarían a fabricar unas cuantas piezas más (ver nota 9).

94. Aguilar Escobar, A.: Cañones de bronce, pp. 129-130.

95. Calvo Poyato, J.: «La industria militar española», pp. 54-55. 
solo se permitió la venta de armas al ejército, lo que fue una clara realidad desde comienzos del siglo Xvir. A causa de las dificultades económicas de este siglo, la Hacienda pagaba tarde y menos de lo debido, por lo que a veces fue necesario recurrir a ingresos extraordinarios. La producción iría en aumento hasta mediados de siglo, para decaer después ${ }^{96}$. En el siglo xvir ya trabajaban en Placencia cuatro gremios principales, cajeros, cañonistas, chisperos y aparejeros, fundamentalmente los mismos que seguirían haciéndolo en el siglo XviII.

La producción decayó en la segunda mitad del siglo xvir y fue probablemente con el estallido de la Guerra de Sucesión, cuando se tomaron medidas para reactivar la producción con un fuerte control estatal, representado por la creación del cargo de superintendente general, en $1705^{97}$, que sustituía, seguramente con más poderes, al antiguo veedor. El rígido control de la producción por parte de la Administración cedió a partir de 1721, cuando se restableció el sistema de asientos. En ese año firmó el asiento Martín de Isasi-Isasmendi, quien seguramente lo disfrutaría hasta 1735. El asentista debía negociar con los representantes de cada uno de los gremios las condiciones y precios de la elaboración de las piezas y las operaciones de montaje de las armas. Los maestros examinadores se encargaban de verificar la adecuación de las piezas y armas entregadas, que debían ser aceptadas, a lo estipulado en el asiento. El acuerdo fijaba en 12.000 los fusiles anuales que se habían de entregar. Una de las principales novedades que produjo el retorno al sistema de asientos fue la posibilidad de que los armeros volvieran también a fabricar armas para el mercado privado, siempre que no tuvieran contratos pendientes con el rey; pero esta libertad no funcionó bien, bajó la calidad de lo entregado al rey y a veces no se cumplió con las entregas. Todo esto produjo también conflictos entre el asentista y los gremios. Se acusó al asentista de poner sus intereses por delante de los del rey y de hacer que fueran pocos los artesanos que trabajaran para la Corona.

La Corona vio la solución a los problemas en la Real Compañía Guipuzcoana de Caracas. Dado que la Compañía debía dinero al rey, se pensó que una manera de solucionarlo sería entregándole el asiento de abastecimiento de armas de Plasencia. En adelante el asiento se financiaría con cargo a los derechos de navegación devengados por la Compañía ${ }^{98}$, lo que ocurriría a partir de 1735 . De esta manera se pudo pagar a los armeros y la producción creció, sin por ello prescindir del mercado privado. Antes de 1747, cuando las relaciones entre la compañía y la fábrica

96. CARrión, I.: «Sixteenth and Seventeenth Century Arms Production in Gipuzkoa». Proceedings of the XXth International Congress of History of Science (Liége 20-26 July 1997), Vol. VII. Technology and Engineering. Ed. Brepols,Turnhout (Bélgica), 2000.

97. Calvo Poyato, J.: «La industria militar española», p. 58.

98. Algunas noticias al respecto en GÁRATE OJANGUREN, M. ${ }^{a}$ M.: La Real Compañía Guipuzcoana de Caracas. San Sebastián, 1990, pp. 291, 344-45, 468. 
se suspendieron, se producían unos 18.000 fusiles al año. El intento de volver a una administración directa de la empresa (el control de la producción colectiva, se entiende) por el Estado, no daría fruto y en 1753 la Guipuzcoana recuperó el asiento, que mantendría hasta su transformación en Compañía de Filipinas en 1785. La nueva compañía también se encargó del asiento de armas ligeras hasta que los acontecimientos de la guerra de la Convención destruyeran las fábricas vascas y la producción se trasladara a Asturias. Así pues, en este caso los asentistas fueron, cuando los hubo, comerciantes, bien individuales, como Isasi-Isasmendi, bien una compañía por acciones, lo que en el panorama de la primera mitad del siglo XVIII resultaba bastante original.

\section{Del Estado comprador al Estado fabricante: la estatalización de las FÁBRICAS DE ARMAS DESDE LOS AÑOS SESENTA}

Hasta 1759 la figura del Estado contratante (Contractor State), parece haber sido la más extendida en el sector del armamento, con la única excepción de las fábricas de cañones de bronce; pero incluso en estos casos el fundidor siempre fue llamado asentista y mantuvo una personalidad propia. Aunque el siglo XVIII vio aparecer formas de empresas estatales en otros sectores (textil, vidrio, por ejemplo), dentro del programa industrializador de Felipe $\mathrm{V}^{99}$, en el sector del armamento se mantuvo la opción por comprar, en vez de fabricar. Las cosas, sin embargo, iban a cambiar de manera radical en el reinado de Carlos III. El nuevo monarca, preocupado por el creciente poderío británico en la Guerra de Siete Años, hecho manifiesto precisamente el mismo año de su llegada a España de 1759 , cuando las victorias británicas fueron aplastantes ${ }^{100}$, decidió cambiar la política internacional ${ }^{101}$. Ello exigía ejercer un control mucho mayor sobre las empresas estratégicas y conseguir un sustantivo aumento de la producción de armas, tanto en cantidad, como en calidad. El esfuerzo iría acompañado de una culminación en el control de los resortes hacendísticos por parte de la Administración ${ }^{102}$. En consecuencia, desde los años sesenta se desarrolla un

99. GonZÁlez EnCISO, A.: Felipe V: La renovación de España. Sociedad y economía en el reinado del primer Borbón. EUNSA, Pamplona, 2003.

100. McLynn, F.: 1759. The Year Britain Became Master of the World. Atlantic Monthly Press, Nueva York, 2004.

101. No hay que olvidar que el ambiente previo a ese año era ya de decepción y tensiones con la política británica, lo que estaba llevando a España a un rearme que se haría necesario en 1760, nada más llegar el nuevo monarca a Madrid. Cfr. Tellez Alarcia, D.: El ministerio Wall. La «España discreta» del «ministro olvidado». Marcial Pons, Madrid, 2012, pp. 95, 106 y ss.

102. Torres SÁnchez, R.: La llave de todos los tesoros. La Tesorería General de Carlos III. Madrid, Sílex, 2012. 
claro programa nacionalizador en el sector ${ }^{103}$. No está de más recordar los acontecimientos fundamentales.

En el caso de Liérganes, el propósito del monarca parecía haber estado claro en su mente antes de llegar a España, porque el Decreto en el que revocaba los privilegios de Olivares fue inmediato. Luego, las cosas también fueron lo rápido que se pudo: en 1760, intervención técnica; en 1763, gestión directa por la Administración y en 1769 , expropiación consumada ${ }^{104}$. Fue fácil para los gestores del Gobierno enfocar el problema desde sus intereses políticos porque el marqués de Villacastel se habría labrado muchos enemigos. El Decreto de revocación de privilegios, dice Maiso, aporta las razones que lo justifican: «El monopolio perpetuo [que tenía Villacastel] impide la competencia y las ventajas que esta trae», por ello, dice este autor, el monarca no solo tenía autoridad para revocar los privilegios anteriormente concedidos, sino que debía hacerlo porque tales privilegios se oponían al bien público, supuestamente derivado de la competencia ${ }^{105}$. De acuerdo con Maiso, pero el argumento utilizado por los gobernantes era falaz: se acusaba a Villacastel de limitar la competencia con sus privilegios y lo que se intentaba era, precisamente, eliminar cualquier competencia a favor de un propietario aún más fuerte y privilegiado, el propio Estado.

En todo caso, lo que nos preocupa ahora no es tanto la orientación política, como el hecho de que el Estado decidió pasar de comprador a fabricante, de una manera clara y explícita. En el caso de esta fábrica se iba en contra de una tradición de casi 150 años. En la parte positiva de la decisión está el hecho de que la calidad de las piezas de Liérganes había decaído y que tampoco se habían hecho muchos avances tecnológicos. La propiedad estatal intentará hacer esa renovación, pero, como es sabido, fracasará, con lo que al final no hubo renovación tecnológica y se perjudicó tanto al sector empresarial, quitando una oportunidad real de negocio, como al erario, al gastar más con los mismos frutos que antes.

En 1766 le llegó el turno estatalizador a la fábrica de Eugui. En este caso el Gobierno esperó a que expirara el último asiento de Mendinueta, a finales de 1765. De todos modos, en los meses finales de ese año ya estaba dispuesta la comisión que debería trasladarse a Eugui para informar sobre la situación de la empresa y de las medidas que se pudieran tomar para comprar la propiedad a los herederos de Monte Real, lo que se realizaría a comienzos de $1766^{106}$.

103. Un reciente ensayo sobre el programa estatalizador de Carlos III en GonZÁlez EnCISO, A.: «Del contractor state al Estado fabricante. El cambio de propiedad en la fábrica de municiones de Eugui en 1766», Revista de Historia de la Economía y de la Empresa, BBVA, VII (2013), pp. 455-80. 104. Alcala-Zamora, J.: Liérganes y La Cavada, p. 114.

105. Maiso GonzÁlez, J.: La difícil modernización de Cantabria en el siglo XVIII: don Juan F. de Isla y Alvear. Estudio, Santander, 1990, p. 152.

106. AGS, SH, 804, 1. 
Por supuesto, tras algunos años de inactividad, la empresa estaba en muy mal estado y la comisión no dejó de resaltarlo con un tono que de alguna manera demostraba la necesidad de que el Estado se hiciera cargo de una empresa que el egoísmo particular no había sabido gestionar convenientemente ${ }^{107}$. También en Eugui parece evidente el estancamiento tecnológico que sería una de las razones de la nacionalización, pero no es menos evidente que el designio era claro y decidido con seguridad, mucho antes. La nacionalización produjo un aumento de la producción temporal, pero no se mantuvo y, además, el coste fue mucho más crecido que el pagado anteriormente al asentista ${ }^{108}$. También aquí se eliminó una oportunidad de negocio privado para conseguir los mismos frutos con mayor gasto.

El protagonismo estatal se manifestaría en otros casos, la mayoría fallidos de una o de otra manera. En Sevilla, aunque la empresa ya era estatal, hubo cambios importantes en 1767, cuando se inició la gestión directa por el Estado también del proceso de fundición. A partir de ese momento los oficiales de Artillería asumen el control total de la empresa y los fundidores dejan de ser asentistas para pasar a ser funcionarios a sueldo de la Corona. También aquí los motivos inmediatos del cambio fueron de índole técnica, ya que la calidad de la producción con el último asentista no había sido satisfactoria. Además, estaba el motivo de la introducción de la fundición en sólido, considerada como algo necesario. Por eso, Aguilar Escobar señala que «las razones de fondo» del cambio hay que buscarlas en el deseo de Carlos III de convertir la fundición de Sevilla en una gran empresa de armamento capaz de producir en serie las piezas de artillería necesarias para los nuevos retos de la Monarquía ${ }^{109}$, en definitiva, el ideal militar-mercantilista. Ese cambio se reflejará, entre otras cosas, en los nuevos grandes edificios que entonces se diseñan para hacer posible la renovación de la empresa ${ }^{110}$. En cualquier caso, el cambio encaja perfectamente en el programa de total protagonismo estatal en el sector del armamento.

Algo parecido ocurrió en Barcelona. Su fábrica de cañones de bronce ya había tenido alguna ampliación a lo largo de la primera mitad del siglo, pero será precisamente en 1766, coincidiendo con el paso del ingeniero Maritz por allí, antes de ir a Sevilla, cuando comenzaron las obras oportunas para ampliar la fábrica y poder

107. Expedientes varios en AGS, SG, 441.

108. GonZÁlez ENCISO, A.: «Estado militar y empresarios de industrias militares», en Idem, (ed.): Un Estado militar: España, 1650-1820. Actas, Madrid, 2012, pp. 435 et passim. Idem: «Del contractor state al Estado fabricante».

109. Aguilar Escobar, A.: Cañones de bronce, pp. 143-144.

110. Rabanal Yus, A.: Las Reales Fundiciones españolas del siglo XVIII. Servicio de Publicaciones del EME, Madrid, 1990, pp. 101 et passim. 
establecer también las nuevas máquinas de barrenar para el proceso en sólido ${ }^{111}$.

El impulso estatalizador se extendería a la creación de nuevas fábricas de municiones. A partir de 1768 se empezaría la construcción, dependiente de la Secretaría de Guerra, de una nueva fábrica en San Sebastián de la Muga, Gerona, propiciada no solo por la necesidad de aumentar la producción de municiones, sino por las expectativas de un mineral de buena calidad, que también desaparecería en $1794^{112}$. En la siguiente década se continuó con el programa con el establecimiento de la fábrica de Ximena de la Frontera. Su cédula de creación es de 1777 y su objetivo era fabricar «cañones y balería de fierro para surtir las plazas de América»; si bien, la primera fundición no saldría hasta $1780^{113}$. En 1784 comenzaron las obras para el establecimiento de la siderurgia de Orbaiceta. Su establecimiento se ha explicado a veces como respuesta al cierre de la recientemente creada fábrica de Ximena ${ }^{114}$. Es cierto que a raíz de la paz de 1783, la fábrica de Ximena de la Frontera tuvo algunos problemas, pero Alcalá-Zamora ya mostró con claridad que dicha fábrica continuó hasta $1788^{115}$ y para esa época la de Orbaiceta ya estaba en marcha hacía algunos años. Sí puede ser que el cierre de Ximena condujera a la aprobación en Orbaiceta de un «ramo para Indias», que sería ejecutado a raíz de la orden de 1789 que mandaba establecer dos hornos en aquella fábrica con aquel objetivo ${ }^{116}$. La idea de Orbaiceta, pensada solamente para munición, estaría más en consonancia con el peligro, sentido ya desde hacía tiempo, como hemos mencionado, de que Eugui se quedara sin combustible por agotarse los montes cercanos a raíz del aumento de producción. Tal aumento venía siendo especialmente notable desde $1777^{117}$. En definitiva, a partir de los años sesenta asistimos en el sector del armamento a la sustitución de la gestión encargada a asentistas privados -el Estado contratante-, por la gestión estatal, el Estado fabricante, que hace triunfar en este sector el viejo ideal mercantilista de que «el príncipe sea comerciante», que en el lenguaje de la época significaba, también, propietario de la empresa y fabricante.

111. Idem, p. 147.

112. Idem, pp. 219 y ss.; AlcalÁ-Zamora, J.: Altos hornos, pp. 366-367.

113. Alcalá-Zamora, J.: Altos hornos, pp. 250, 254.

114. Por ejemplo, GÓmEZ CAMPelo, R.: «El envío de municiones navarras a América. Las fábricas de Eugui y Orbaiceta», Príncipe de Viana. Anejo 13, LIII, (1991), pp. 311-319. La autora cita en esto a LARRAÑAGA, R.: Sintesis histórica de la armería vasca.

115. Alcalá-Zamora, J.: Altos hornos, p. 260.

116. Gómez Campelo, R.: «El envío de municiones», pp. 316-317.

117. Arnaiz, M. de: «Breve reseña de las fábricas de fundición de hierro de Navarra», en Memorial de Artillería, VI, 1850, pp. 49-91; GonZÁlEz EnCISO, A.: «Military Expenditure and Entrepreneurial Promotion in Modern Spain: An Unsuccessful Expedient. The Example of the Eugui Munitions Factory», en CONWAY, S. y TORRES SÁnchez, R. (eds.): The Spending of States. Military Expenditure During the Long Eighteenth Century: Patterns, Organisation and consequences, 1650-1815. VDM, Saarbrücken, 2011, p. 302. 


\section{Conclusiones}

Ante el problema del abastecimiento de armas, la elección entre fabricar o comprar parece haber perseguido a todos los gobernantes españoles de la Edad Moderna. El hecho de que los principales conflictos de la Monarquía se desarrollaran durante los siglos XVI y XviI fuera de tierras peninsulares, y curiosamente en lugares como los Países Bajos, o el norte de Italia, donde la producción de armas estaba muy desarrollada, condicionó seguramente la evolución de este sector en la Península, a pesar de que las primeras bases del sector se hubieran establecido ya durante el reinado de los Reyes Católicos, o incluso antes. Desde esos mismos momentos se notan tendencias diferentes: cuando se trata de armas ligeras, se deja la producción a los gremios, aunque se les someta a un control cada vez mayor; luego, está el caso de la Armería Real de Eugui (1536), seguramente controlada de manera directa por la Administración, pero aún no para fabricar armas, sino corazas y cascos. Cuando se trata de cañones de bronce, el Estado lo dejó de momento en manos de particulares, pero bajo un régimen de exclusividad. Así pues, en el siglo xvi parece haber dominado el Estado comprador, si bien con clara vocación de control.

En el siglo XVII esta tendencia al control se fortalecerá en algunos aspectos y se modificará en otros. Primero, se mantuvo la situación en Eugui, aunque su producción se vio sometida a continuos altibajos, traslados a Tolosa y ensayos con operarios extranjeros ${ }^{118}$; segundo, el Estado compró la fábrica de Sevilla en 1634, aunque los asentistas aún gozaran de bastante libertad. Por otra parte, en aparente contraste con un Estado que mantiene sus empresas y compra otras, habría que señalar la desaparición de la fábrica de Málaga, el mal funcionamiento de una fundición de cañones de bronce en Zaragoza, cuya producción habría resultado más cara que la de Sevilla ${ }^{119}$, y la misma crisis productiva en Sevilla; además, podemos preguntarnos qué pasaba exactamente en Barcelona.

Para hacer aún más controvertido el contraste, vemos cómo en el siglo XviI además de mantenerse una empresa estatal, aparecer otra y decaer algunas, surgen tres nuevas empresas, esta vez privadas: la de cañones de hierro de Liérganes y La Cavada, la posterior de Corduente (Molina de Aragón) y la de municiones de hierro de Eugui, reestructurada por Aldaz, que implica, a la vez, la definitiva desaparición de la armería real a duras penas mantenida hasta entonces. Todo ello supone, a la vez, el intento del desarrollo del sector de la fundición de hierro, abandonado en algún momento del siglo $\mathrm{XvI}^{120}$, y que se recomenzaría, significativamente, con asentistas particulares. Si en el siglo xvi parece haber dominado el Estado comprador,

118. Un breve resumen de los principales datos en la bibliografía disponible en GonZÁLEZ ENCISO, A.: «Empresarios navarros», pp. 172-174.

119. Dos noticias al respecto en Aguilar Escobar, A.: Cañones de bronce, pp. 76-77.

120. SuÁrez Menéndez, R.: «La industria militar», p. 218. 
decíamos, en el siglo Xvil la balanza se sigue inclinando a favor de los asentistas, sencillamente porque, ante la falta de capital estatal para mayores inversiones -el único esfuerzo en este sentido parece haberse hecho en Sevilla y tímidamente-, el asentista resolvía el problema, aunque el Estado no pagara siempre bien.

En la primera mitad del siglo XviII la situación tiene un marcado contraste entre el fortalecimiento del control e inversión estatales en Sevilla y Barcelona, y el aumento de los privilegios del asentista de Liérganes. En Eugui no se dieron tantos privilegios, pero sí los suficientes y, en todo caso, es evidente que hasta los años sesenta se mantuvo la apuesta por los asentistas. También en la fabricación de armas ligeras entre los fabricantes vascos el rígido control establecido durante la Guerra de Sucesión, dio paso a un régimen de mayor libertad de fabricantes y asentistas. Quede claro, en todo caso, que como ya había ocurrido en el siglo xvi,, se trata de unos asentistas controlados cada vez más y que trabajan en un régimen de estricta exclusividad para la demanda estatal.

De todas formas, el giro de Carlos III respecto a cañones y municiones en particular, plantea el problema de hasta qué punto la apuesta por los asentistas había sido sincera o simplemente pragmática. A la hora de la verdad, el monarca español supuestamente más poderoso del siglo, optó claramente por el protagonismo estatal. ¿Podemos decir que había terminado así el Estado contratante en el sector del armamento pesado? Con independencia del problema teórico que se plantea (¿ sigue siendo un contractor state el Estado fabricante?) en el que ahora no vamos a entrar, lo que está claro es que el cambio no dio los frutos esperados. Los acontecimientos de 1794 dieron al traste con buena parte del programa, en este caso por una razón estratégica: las tres fábricas de municiones que entonces existían estaban ubicadas muy cerca de la frontera francesa y fueron destruidas por las tropas invasoras.

¿Cómo resolvía el Estado español el problema de su abastecimiento de armas en los siglos XVII y XVIII, nos preguntábamos al inicio del trabajo? Como hemos visto, la respuesta es muy variada. Las razones de la variedad tienen que ver tanto con cuestiones técnicas, como de oportunidad política. Asentistas y políticos, en efecto, se encuentran estrechamente relacionados y la suerte de los asentistas dependía de las decisiones políticas. Aunque en general, hasta 1760 dominó el recurso a los asentistas, la verdad es que cuando la técnica y la tradición lo permitían (cañones de bronce), se recurrió a la propiedad estatal. Salvo raras excepciones, los asentistas suelen aparecer como un elemento necesario pero incómodo. Se mantiene la idea de que el asentista busca sobre todo un beneficio particular que sería contrario a los intereses del rey. Carlos III se creyó con la fuerza suficiente para poder, de una vez por todas, controlar todo el sector del armamento sin intermediarios. Al fin, todo beneficio caería en la Administración y ella misma podría intervenir todos los procesos. Por los resultados, parece que se equivocó. 


\section{Bibligrafía}

Adaro Ruiz-Falcó, L.: Los comienzos de las fábricas de municiones gruesas de Trubia y de armas de Oviedo: 1792-1799. Imprenta La Cruz, Oviedo, 1986.

Aguilar Escobar, A.: Cañones de bronce para el Ejército. Historia de la Real Fundición de Sevilla en el siglo XVIII. Ministerio de Defensa, Madrid, 2010.

Alcalá-Zamora, J.: Altos hornos y poder naval en la España de la Edad Moderna. Real Academia de la Historia, Madrid, 1999.

PMid:10326647

—: Liérganes y La Cavada. Historia de los primeros altos hornos españoles (1622-1834). Estudio, Santander, 2004.

Andueza Unanua, P.: «De padre cerero a hijo marqués: José de Aldaz y Aguirre, marqués de Monte Real», en González Enciso, A. (ed.): Navarros en la Monarquía española en el siglo XVIII. EUNSA, Pamplona, 2007, pp. 89-122.

Aquerreta, S.: «La casa de Arizcun, 1725-1742: Las estrategias financieras de un hombre de negocios en el Madrid de la Ilustración», en Ferrer Benimelli, J. A. (dir.): El conde de Aranda y su tiempo. Institución Fernando el Católico, Zaragoza, 2000, pp. 659-78.

- (coord.): Francisco Mendinueta: finanzas y mecenazgo en la España del siglo XVIII. EUNSA, Pamplona, 2002.

PMid:12196049

- : «De su cuenta y riesgo y por vía de asiento". Trayectoria y negocios de Francisco Mendinueta (1744-1763)», en Aquerreta, S. (coord.): Francisco de Mendinueta: finanzas y mecenazgo en la España del siglo XVIII. EUNSA, Pamplona, 2002, pp. 77-100.

Arnaiz, M. de: «Breve reseña de las fábricas de fundición de hierro de Navarra», en Memorial de Artillería, VI (1850), pp. 49-91.

BARretT, E.: «Copper in New Spain's Eighteenth Century Economy. Crisis and Resolution», en Jabrbuch für Geschichte von Staat, Wirtschaft und Gesellschaft Lateinamerikas, 18 (1981), pp. 73-96.

Calvo Poyato, J.: «La industria militar española durante la Guerra de Sucesión», en Revista de Historia Militar, 66 (1989), pp. 51-71.

CARmona Badía, X.: «Antonio Raimundo Ibáñez, un empresario en el filo de dos épocas», en Ocampo SuÁrez-VAldés, J.: Empresas y empresarios en el norte de España (siglo XVIII). Trea, Oviedo, 2012, pp. 69-90.

CARrasco, A.: «Apuntes para la historia de la fundición de artillería de bronce en España», en Memorial de Artillería, XV (1887), pp. 49-58 y 166-179.

Carrión, I.: «Sixteenth and Seventeenth Century Arms Production in Gipuzkoa». Proceedings of the XXth International Congress of History of Science (Liége 20-26 July 1997), vol. VII. Technology and Engineering. Brepols, Turnhout (Bélgica), 2000.

Cipolla, C.: Guns, Sails and Empires. Minerva Press, Nueva York, 1965.

Gárate Ojanguren, Mª M.: La Real Compañia Guipuzcoana de Caracas. Caja de Ahorros Municipal de San Sebastián, San Sebastián, 1990. 
Gil Ossorio, F.: Organización de la artillería española en el siglo XVIII. 1, la época de los artilleros empíricos de las guerras de Felipe V. Servicio Histórico Militar, Madrid, 1981.

Gómez Campelo, R.: «El envío de municiones navarras a América. Las fábricas de Eugui y Orbaiceta», Príncipe de Viana. Anejo 13, LIII (1991), pp. 311-19.

González Enciso, A.: Felipe V: La renovación de España. Sociedad y economía en el reinado del primer Borbón. EUNSA, Pamplona, 2003.

— : «La promoción industrial en la España Moderna: intervención pública e iniciativa privada», en Riвот García, L. A. y De Rosa, L. (dirs.): Industria y Época Moderna. Actas, Madrid, 2000, pp. 15-46.

- : «Empresarios navarros en la industria de municiones para la artillería», en TORRES SÁNCHEZ, R. (ed.): Volver a la "hora navarra». La contribución navarra a la construcción de la Monarquía española en el siglo XVIII. EUNSA, Pamplona, 2010, pp. 159-212.

—-: El nacimiento del capitalismo en Europa. Eunate, Pamplona, 2011.

PMid:22091420 PMCid:PMC3198603

- : «Military Expenditure and Entrepreneurial Promotion in Modern Spain: An Unsuccessful Expedient. The Example of the Eugui Munitions Factory», en Conway, S. y Torres Sánchez, R. (eds.): The Spending of States. Military Expenditure during the Long Eighteenth Century: Patterns, Organisation and consequences, 1650-1815. VDM, Saarbrücken, 2011, pp. 285-312.

— : «La cultura mercantil en la España Moderna y la mentalidad empresarial», en Príncipe de Viana, 254 (2011), pp. 13-36.

- : «Buying cannons outside: when, why, how many? The supplying of foreign iron cannons for the Spanish Navy in the Eighteenth Century», en Harding, R. y Solbes FERRI, S. (coords.): The Contractor State and its Implications, 1659-1815. Universidad de Las Palmas, Las Palmas de Gran Canaria, 2012, pp. 135-58.

—-: «Estado militar y empresarios de industrias militares», en González Enciso, A. (ed.): Un Estado militar: España, 1650-1820. Actas, Madrid, 2012, pp. 423-47.

- : «La renovación del asiento de transporte de municiones y armas en 1793 y el protagonismo de una familia navarra», en Memoria y Civilización, 15 (2012), pp. 51-69.

- : «Del contractor state al Estado fabricante. El cambio de propiedad en la fábrica de municiones de Eugui en 1766», en Revista de Historia de la Economía y de la Empresa, BBVA, VII (2013), pp. 455-80.

Helguera Quijada, J.: «De La Cavada a Trubia. Intervencionismo estatal y cambio tecnológico en las fundiciones de artillería del norte de España (1760-1800)», en Ocampo SuÁrez-Valdés, J.: Empresa y empresarios en el norte de España (Siglo XVIII). Trea, Oviedo.

Hernández Escayola, C.: Negocio y servicio: Finanzas públicas y bombres de negocios en Navarra en la primera mitad del siglo XVIII. EUNSA, Pamplona, 2004.

Jiménez Estrella, A.: «Asentistas militares y fraude en torno al abastecimiento de pólvora en el reino de Granada (siglo xvi)», en Investigaciones Históricas, 30 (2010), pp. 11-30.

Kamen, H.: La Guerra de Sucesión en España, 1700-1715. Grijalbo, Barcelona 1974.

Larrañaga, R.: Síntesis Histórica de la Armería Vasca. Caja de Ahorros Provincial de Guipúzcoa, San Sebastián, 1981. 
Maiso González, J.: La difícil modernización de Cantabria en el siglo XVIII: D. Juan F. de Isla y Alvear. Estudio, Santander, 1990.

MARTí, R.: Cataluña armería de los Borbones. Las armas y los armeros de Ripoll, Barcelona, Manresa, Igualada... de 1714 a 1794. Salvatella, Barcelona, 2004.

McLynn, F.: 1759. The Year Britain Became Master of the World. Atlantic Monthly Press, Nueva York, 2004.

Ocete Rubio, R.: Catálogo de armas. Junta de Andalucía, Sevilla, 2008.

Rabanal Yus, A.: Las Reales Fábricas de Eugui y Orbaiceta. Institución Príncipe de Viana, Pamplona, 1987.

Rodríguez GonzÁlez, A. R.: Trafalgar y el conflicto naval anglo-español del siglo XVIII. Madrid, Actas, 2005.

SuÁrez Menéndez, R.: «La industria militar española anterior a 1808», en Militaria. Revista de Cultura Militar, 7 (1995), p. 219.

Téllez Alarcia, D.: El ministerio Wall. La «España discreta» del «ministro olvidado». Marcial Pons, Madrid, 2012.

Torres Sánchez, R. (ed.): Capitalismo mercantil en la España del siglo XVIII. EUNSA, Pamplona, 2000.

- : «El gran negocio de la época, la provisión de víveres al ejército por Francisco Mendinueta (1744-1763)», en Aquerreta, S. (coord.): Francisco Mendinueta: finanzas y mecenazgo en la España del siglo XVIII. EUNSA, Pamplona, 2002, pp. 101-134.

—-: La llave de todos los tesoros. La Tesorería General de Carlos III. Madrid, Sílex, 2012.

Uztariz, J. de: Theorica y practica de Comercio y de Marina. Aguilar, Madrid, 1968.

Vázquez de Prada, V.: «Los hombres de negocios de Burgos (s. XIV-XVI), ejemplo de mentalidad emprendedora», en Klep, P. y VAN Cauwenberghe, E. (eds.): Entrepreneurship and the Transformation of the Economy (10th-20th Centuries). Essays in Honour of Herman Van der Wee. Leuven University Press, Lovaina, 1994.

Vega Viguera, E. de la: Sevilla y la Real Fundición de Cañones. Guadalquivir, Sevilla, 1992. 